\title{
Microbial communities mediating algal detritus turnover under anaerobic conditions
}

\author{
Jessica M Morrison ${ }^{1}$, Chelsea L Murphy $^{1}$ ， Kristina Baker ${ }^{1}$ ， Richard M. Zamor ${ }^{2}$, Steve J Nikolai ${ }^{2}$, Shawn \\ Wilder $^{3}$, Mostafa S Elshahed ${ }^{1}$, Noha H Youssef ${ }^{\text {Corresp. } 1}$ \\ 1 Department of Microbiology and Molecular Genetics, Oklahoma State University, Stillwater, OK, USA \\ 2 Grand River Dam Authority, Vinita, OK, USA \\ 3 Department of Integrative Biology, Oklahoma State University, Stillwater, OK, United States \\ Corresponding Author: Noha H Youssef \\ Email address: noha@okstate.edu
}

Background. Algae encompass a wide array of photosynthetic organisms that are ubiquitously distributed in aquatic and terrestrial habitats. Algal species often bloom in aquatic ecosystems, providing a significant autochthonous carbon input to the deeper anoxic layers in stratified water bodies. In addition, various algal species have been touted as promising candidates for anaerobic biogas production from biomass. Surprisingly, in spite of its ecological and economic relevance, the microbial community involved in algal detritus turnover under anaerobic conditions remains largely unexplored. Results. Here, we characterized the microbial communities mediating the degradation of Chlorella vulgaris (Chlorophyta), Chara sp. strain IWP1 (Charophyceae), and kelp Ascophyllum nodosum (phylum Phaeophyceae), using sediments from an anaerobic spring (Zodlteone spring, OK; ZDT), sludge from a secondary digester in a local wastewater treatment plant (Stillwater, OK; WWT), and deeper anoxic layers from a seasonally stratified lake (Grand Lake $\mathrm{O}^{\prime}$ the Cherokees, OK; GL) as inoculum sources. Within all enrichments, the majority of algal biomass was metabolized within 13-16 weeks, and the process was accompanied by an increase in cell numbers and a decrease in community diversity. Community surveys based on the V4 region of the 16S rRNA gene identified different lineages belonging to the phyla Bacteroidetes, Proteobacteria (alpha, delta, gamma, and epsilon classes),

Spirochaetes, and Firmicutes that were selectively abundant under various substrate and inoculum conditions. Within all kelp enrichments, the microbial communities structures at the conclusion of the experiment were highly similar regardless of the enrichment source, and were dominated by the genus Clostridium, or family Veillonellaceae within the Firmicutes. In all other enrichments the final microbial community was dependent on the inoculum source, rather than the type of algae utilized as substrate. Lineages enriched included the uncultured groups VadinBC27 and WCHB1-69 within the Bacteroidetes, genus Spirochaeta and the uncultured group SHA-4 within Spirochaetes, Ruminococcaceae, 
Lachnospiraceae, Yongiibacter, Geosporobacter, and Acidaminobacter within the Firmicutes, and genera Kluyvera, Pantoea, Edwardsiella and Aeromonas, and Buttiauxella within the Gamma-Proteobaceteria order Enterobacteriales. Conclusions. Our results represent the first systematic survey of microbial communities mediating turnover of algal biomass under anaerobic conditions, and highlights the diversity of lineages putatively involved in the degradation process. 


\section{Microbial communities mediating algal detritus turnover under} anaerobic conditions

Jessica M. Morrison*1, Chelsea L. Murphy*1, Kristina Baker ${ }^{1}$, Richard M. Zamor ${ }^{2}$, Steve Nikolai $^{2}$, Shawn Wilder ${ }^{3}$, Mostafa S. Elshahed ${ }^{1}$, Noha H. Youssef ${ }^{1}$

${ }^{1}$ Department of Microbiology and Molecular Genetics, Oklahoma State University, Stillwater, OK, USA

${ }^{2}$ Grand River Dam Authority (GRDA), Vinita, OK, USA

${ }^{3}$ Department of Integrative Biology, Oklahoma State University, Stillwater, OK, USA

*The authors contributed equally to the work

Running Title: Degradation of algal biomass by anaerobes

${ }^{1}$ Corresponding author. Address: $1110 \mathrm{~S}$. Innovation way, Stillwater, Oklahoma 74074 USA.

Phone: 1-405-744-1192, Fax. 1-405-744-1112 email: Noha@,Okstate.edu 
Abstract

40

41

42

\section{Background.}

Algae encompass a wide array of photosynthetic organisms that are ubiquitously distributed in aquatic and terrestrial habitats. Algal species often bloom in aquatic ecosystems, providing a significant autochthonous carbon input to the deeper anoxic layers in stratified water bodies. In addition, various algal species have been touted as promising candidates for anaerobic biogas production from biomass. Surprisingly, in spite of its ecological and economic relevance, the microbial community involved in algal detritus turnover under anaerobic conditions remains largely unexplored.

\section{Results.}

Here, we characterized the microbial communities mediating the degradation of Chlorella vulgaris (Chlorophyta), Chara sp. strain IWP1 (Charophyceae), and kelp Ascophyllum nodosum (phylum Phaeophyceae), using sediments from an anaerobic spring (Zodlteone spring, OK; ZDT), sludge from a secondary digester in a local wastewater treatment plant (Stillwater, OK; WWT), and deeper anoxic layers from a seasonally stratified lake (Grand Lake O' the Cherokees, OK; GL) as inoculum sources. Within all enrichments, the majority of algal biomass was metabolized within 13-16 weeks, and the process was accompanied by an increase in cell numbers and a decrease in community diversity. Community surveys based on the V4 region of the 16S rRNA gene identified different lineages belonging to the phyla Bacteroidetes,

Proteobacteria (alpha, delta, gamma, and epsilon classes), Spirochaetes, and Firmicutes that were selectively abundant under various substrate and inoculum conditions. Within all kelp enrichments, the microbial communities structures at the conclusion of the experiment were highly similar regardless of the inoculum source, and were dominated by the genus Clostridium, 
62 or family Veillonellaceae within the Firmicutes. In all other enrichments the final microbial

63 community was dependent on the inoculum source, rather than the type of algae utilized as

64 substrate. Lineages enriched included the uncultured groups VadinBC27 and WCHB1-69 within

65 the Bacteroidetes, genus Spirochaeta and the uncultured group SHA-4 within Spirochaetes,

66 Ruminococcaceae, Lachnospiraceae, Yongiibacter, Geosporobacter, and Acidaminobacter

67 within the Firmicutes, and genera Kluyvera, Pantoea, Edwardsiella, Aeromonas, and

68 Buttiauxella within the Gamma-Proteobaceteria order Enterobacteriales.

69 Conclusions. Our results represent the first systematic survey of microbial communities

70 mediating turnover of algal biomass under anaerobic conditions, and highlights the diversity of

71 lineages putatively involved in the degradation process. 
74 Algae represent a globally distributed group of organisms that are capable of oxygenic photosynthesis. While prevalent in aquatic marine and freshwater habitats (Cole 1982), algal taxa are also encountered in terrestrial ecosystems such as soil, rocks, and ice/snow (Hoffmann 1989). Collectively, algal species play an important role in global carbon, nitrogen, sulfur, and phosphorus cycling (Vanni 2002). Taxonomically, algae are polyphyletic, and are encountered within multiple eukaryotic phyla such as the Alveolata (e.g., dinoflagellates), Stramenopiles (e.g., Bacillariophyceae, Chrysophyceae, Eustigmatophyceae), Viridiplanta (e.g., Chlorophyta), in addition to exclusively algal phyla such as the Euglenozoa, Cryptomonads, Haptophyta, and Rhodophyta (Amaral-Zettler 2014). In addition to their complex evolutionary origin, these organisms exhibit a wide array of morphological diversity, pigments, ecological distribution, cellular composition, genome size, and cell wall structure.

A major characteristic of many algal taxa is their fast growth rate, enabling them to form conspicuous seasonal blooms under the appropriate environmental conditions. Such blooms are often associated with elevated nutrient (e.g., nitrogen and/or phosphorus) levels in the ecosystem, often resulting from anthropogenic inputs (e.g., sewage, industrial waste, and fertilizers) (Hallegraeff 1993), as well as from destratification and nutrients resuspension (Wetzel 2001).

90 Classical examples of freshwater algal blooms involve members of the green algae

91 (Chlorophyceae), whose blooms are often encountered in lakes and other freshwater habitats

92 (Hoshaw \& Mccourt 1988), Chara blooms (commonly called Muskgrass), which seasonally

93 occur in ponds and lakes and cause a strong and unpleasant musky odor (Durborow 2014), as

94 well as Diatoms, most commonly encountered in lakes (Sommer et al. 2012; Sommer et al.

95 1986). Fast growth is also a characteristic of many annual or perennial macroscopic taxa. The 
96 classical example of such taxa is the brown algae or Kelp (class Phaeophyceae), which is

97 believed to be one of the most productive photosynthetic organisms and tend to attain long

98 lengths at a very fast elongation rate ( $\sim 50-60 \mathrm{~cm} /$ day) (Reed et al. 2008).

99 Algae provide a large input of organic carbon into aquatic ecosystems such as coastal

100 kelp forests (Mann 1988), meromictic and seasonally stratified lakes (Gies et al. 2014; Xia et al.

101 2016; Youssef et al. 2015), and coastal areas within marine environments (e.g., the North Sea

102 (Boon et al. 1998)). When blooming subsides, the algal detritus sinks and provides a substantial

103 organic carbon source to microbial communities within the ecosystem (Hecky \& Hesslein 1995).

104 Algal degradation in aquatic habitats commences at or near the water surface by the microbial

105 phycosphere: aerobic heterotrophic bacteria that are physically attached to algal cells (Buchan et

106 al. 2014). However, a significant fraction of algal detritus reaches the lower strata of these water

107 bodies, providing a considerable autochthonous contribution to the carbon input in benthic layers

108 within such ecosystems (Ask et al. 2009; Hecky \& Hesslein 1995). Sinking of algal detritus and

109 the subsequent increase in carbon input result in the development of anoxic conditions in the

110 lower strata and, hence, seasonal stratification. The size, intensity, and duration of these bloom-

111 mediated anoxic zones are expected to be accentuated by future global warming trends (Paerl \&

112 Otten 2013). Surprisingly, while a large body of research has been conducted on elucidating the

113 microbial community composition of the algal phycosphere in the aerobic surficial marine (Amin

114 et al. 2012; Hasegawa et al. 2007; Sapp et al. 2007), and freshwater habitats (Bagatini et al.

115 2014; Cai et al. 2014; Dittami et al. 2016; Eigemann et al. 2013; Jones et al. 2013; Muylaert et al.

116 2002), a surprising lack of knowledge exists regarding the microbial community and patterns of

117 algal turnover under the anoxic conditions in the lower layers of stratified water bodies.

118 In addition to the importance of anaerobic degradation of algal biomass to the carbon 
119 cycle in aquatic environments, the process has recently received additional attention as an

120 integral component in algal biofuels production schemes. Direct conversion of kelp to methane

121 (Cannell 1990; Prabandono \& Amin 2015; Ramaraj et al. 2016) has been proposed as a

122 promising approach for biogas production (Samson \& Leduy 1982; Vanegas \& Bartlett 2013;

123 Vergara-Fernandez et al. 2008; Wiley et al. 2011; Yen \& Brune 2007; Yuan et al. 2011). The

124 high fat content of multiple algal taxa, e.g., Chlorella sp. (Guckert \& Cooksey 1990; Hu et al.

125 2008), and Chara sp. (Omer 2013), has prompted research into their large scale production in

126 artificial ponds, and subsequent extraction of their oil content as biodiesel (Cannell 1990;

127 Moazami et al. 2012; Prabandono \& Amin 2015; Ramaraj et al. 2016). The economy of the

128 process is further enhanced by anaerobic digestion of the algal detritus to produce methane as an

129 additional source (Cannell 1990; Prabandono \& Amin 2015; Ramaraj et al. 2016) using sludge

130 from anaerobic wastewater treatment plants as the inoculum source (Bohutskyi et al. 2015).

131 While various aspects of the engineering and performance have been studied, there is very little

132 documentation of the identity of the microbial community that is mediating algal detritus

133 turnover under these anaerobic conditions.

134 Here, we sought to characterize patterns of algal turnover under anaerobic conditions, and

135 identify members of the microbial community involved in the degradation of various

136 ecologically and economically relevant algal taxa. The process was investigated in enrichments

137 derived from three anaerobic habitats that either exhibit seasonal algal blooming, or highly

138 eutrophic environments that receive a high input of organic compounds and previously shown to

139 harbor a high level of microbial diversity. To our knowledge, this is the first study that

140 systematically characterized the microbial community associated with algal degradation under

141 anaerobic conditions. 
143 Algal species (substrates/ carbon source). We evaluated the microbial community mediating

144 algal detritus degradation by setting enrichments with various types of algal biomass as the only

145 source of carbon. Three different algal species were examined: 1. Axenic Chlorella vulgaris

146 strain UTEX 2714 (phylum Chlorophyta), representing green algae that are known to bloom

147 during summer months (June-September) in multiple freshwater bodies within the US. Strain

148 UTEX 2714 was obtained from the University of Texas at Austin Algal Culture collection, and

149 cultures were maintained on proteose medium plates (composition g.1-1 $: \mathrm{NaNO}_{3}, 0.25$;

$150 \mathrm{CaCl}_{2} .2 \mathrm{H}_{2} \mathrm{O}, 0.025, \mathrm{MgSO}_{4} .7 \mathrm{H}_{2} \mathrm{O}, 0.075 ; \mathrm{K}_{2} \mathrm{HPO}_{4}, 0.075, \mathrm{KH}_{2} \mathrm{PO}_{4}, 0.175, \mathrm{NaCl}, 0.025 ;$

151 proteose peptone, 1, agar, 15) at $22 \pm 3{ }^{\circ} \mathrm{C}$. Fluorescent light was used (3500 lux) on a 16:8 hours

152 light to dark cycle. Cultures were harvested by scraping the growth on the surface of agar plates,

153 and the resulting biomass was used as the carbon source. 2. Chara sp. strain IWP: Mats of Chara

154 (class Charophyceae) were obtained from a local pond (Innovation Way Pond in Stillwater, OK, 155 coordinates N 366'37.75" W 976'44.72”) in August 2015, and identified using morphological

156 and microscopic analysis as Chara sp. Chara is known to grow locally in ponds in Oklahoma

157 and peak around June-September (Bill Henley, personal communication). Samples collected

158 were thoroughly washed and soaked in DI water for 2 hours, to remove other associated biomass,

159 before they were centrifuged and the resulting biomass was used as the carbon source to

160 represent class Charophyceae. 3. Kelp: Due to the geographical location of the study and brown

161 algae being common occurrences in marine environments, we were not able to obtain a fresh

162 kelp sample to be used as a substrate. Alternatively, Ascophyllum nodosum (phylum

163 Phaeophyceae) representing brown algae was obtained as a whole dried powder from a local

164 provider (Starwest Botanicals ${ }^{\circledR}$, Sacramento, CA) and directly used as the carbon source. 
165 It is worth noting that, with the exception of the axenic Chlorella culture, the Chara and the kelp

166 samples were not guaranteed axenic and a minimal input of bacteria with the carbon source in

167 these enrichment bottles could not be ruled out.

168 Enrichment (inoculum) sources.

169 Grand Lake (GL). Samples were obtained from Grand Lake O’ the Cherokees (hereafter Grand

170 Lake) to investigate the microbial community involved in algal turnover. The lake is a large (188

$171 \mathrm{Km}^{2}$ ) man-made lake in Northeastern OK operated by the Grand River Dam Authority, which

172 keeps continuous records of the lake water geochemistry. During summer months (starting in

173 June), large areas of the lake become seasonally stratified, with deeper layers (June-September)

174 becoming completely anoxic. Within these sites, surface chlorophyl1-a concentration peaks in

175 May-July, followed by algal biomass sinking to deeper anaerobic layer in September (Figure

176 S1). Sampling from the hypolimnion of Tree and Dream sites in GL occurred in September 2015

177 using a 4.0-L Van Dorn Bottle. Whole water samples were stored on ice until processed in the

178 laboratory where the lake water was centrifuged under anaerobic conditions to collect biomass

179 used as inoculum source.

180 Wastewater Treatment Plant (WWT). While wastewater treatment reactors do not represent an

181 algae rich habitat, the use of WWT material as an inoculum for biogas production from algal

182 biomass sources has been gaining considerable attention (Ward et al. 2014). The process is

183 justified by the high organic content and adaptation to organic matter turnover under anaerobic

184 conditions, coupled to the ready availability of WWT inocula (Sialve et al. 2009). Various

185 aspects of the engineering, kinetics, and the economy of the process, as well as optimization of

186 the inoculum load and substrate load, and algae pretreatment methods have been investigated

187 (Hlavínek et al. 2016; Mudhoo 2012; Nabarlatz et al. 2013; Ramaraj et al. 2016; Samson \& 
188 Leduy 1982; Vergara-Fernandez et al. 2008; Ward et al. 2014), but little research on the identity

189 of microorganisms mediating such process has been conducted. Samples were obtained from

190 secondary treatment sludge in the city of Stillwater, OK wastewater treatment plant in September

191 2015. The sample was collected anaerobically and transferred to the laboratory (5 miles away),

192 where they were promptly centrifuged under anaerobic conditions and used as inoculum source.

193 Zodletone Spring (ZDT). Zodletone spring is an anaerobic surficial spring in southwestern OK

$194\left(35^{\circ} 0^{\prime} 9^{\prime \prime} \mathrm{N} 98^{\circ} 41^{\prime} 17^{\prime \prime} \mathrm{W}\right)$. Due to the constant ejection of sulfide laden water from the spring

195 source, the shallow spring is light exposed, yet mostly anoxic (Buhring et al. 2011). The

196 microbial community in the spring has been extensively investigated (Coveley et al. 2015;

197 Youssef et al. 2010), and the spring harbors a highly diverse community of phototrophs,

198 chemolithotrophs, and heterotrophs. Samples were collected from Zodletone spring source in

199 August 2015 in a filled mason jar (to maintain anoxic conditions), transferred to the laboratory at

$2004^{\circ} \mathrm{C}$ and used as inoculum source on the same day of sampling.

201 Enrichments setup. Enrichments were prepared in $120 \mathrm{ml}$ serum bottles under anaerobic

202 conditions. Nine different treatments (three algal substrates $\times$ three different inoculum sources)

203 were set up in triplicates. Serum bottles contained $45 \mathrm{ml}$ of an anoxic solution containing (per

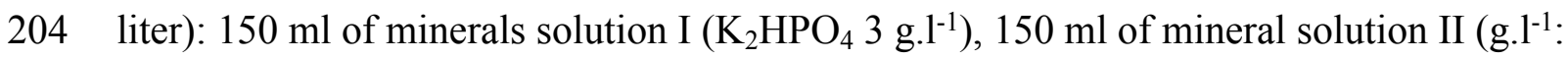

$205 \mathrm{KH}_{2} \mathrm{PO}_{4}, 3 ;\left(\mathrm{NH}_{4}\right)_{2} \mathrm{SO}_{4}, 6 ; \mathrm{NaCl}, 6 ; \mathrm{MgSO}_{4} .7 \mathrm{H}_{2} \mathrm{O}, 0.6$, and $\left.\mathrm{CaCl}_{2} .2 \mathrm{H}_{2} \mathrm{O}, 0.6\right), 10 \mathrm{ml}$ Balch

206 vitamins solution (mg. $\mathrm{l}^{-1}$ : biotin, 2; folic acid, 2; pyridoxine- $\mathrm{HCl}, 10$; thiamine- $\mathrm{HCl}, 5$;

207 riboflavin, 5; nicotinic acid, 5; calcium pantothenate, 5; vitamin B12, 0.1; p-aminobenzoic acid,

2085 ; lipoic acid, 5), $1 \mathrm{ml}$ of Wolin's metal solution (g. $\mathrm{l}^{-1}$ : EDTA, 0.5; $\mathrm{MgSO}_{4} \cdot 6 \mathrm{H}_{2} \mathrm{O}, 3.0$;

$209 \mathrm{MnSO}_{4} \cdot \mathrm{H}_{2} \mathrm{O}, 0.5 ; \mathrm{NaCl}, 1 ; \mathrm{CaCl}_{2} .2 \mathrm{H}_{2} \mathrm{O}, 0.1 ; \mathrm{FeSO}_{4} .7 \mathrm{H}_{2} \mathrm{O}, 0.1 ; \mathrm{ZnSO}_{4} .7 \mathrm{H}_{2} \mathrm{O}, 0.1 ; \mathrm{CuSO}_{4} .7 \mathrm{H}_{2} 0$,

$210 \quad$ 0.01; $\mathrm{AlK}\left(\mathrm{SO}_{4}\right)_{2}, 0.01 ; \mathrm{Na}_{2} \mathrm{MoO}_{4} .2 \mathrm{H}_{2} 0,0.01$; boric acid, $0.01 ; \mathrm{Na}_{2} \mathrm{SeO}_{4}, 0.005 ; \mathrm{NiCl}_{2} .6 \mathrm{H}_{2} 0$, 
$\left.2110.003 ; \mathrm{CoCl}_{2} \cdot 6 \mathrm{H}_{2} 0,0.1\right)$. The media were amended with L-cysteine hydrochloride $(0.05 \mathrm{~g} / \mathrm{l}$ final

212 concentration) as a reductant, and resazurin ( $0.0001 \%$ final concentration $)$ as a redox indicator,

213 boiled under a stream of $\mathrm{N}_{2}$ gas, dispensed in the serum bottles, autoclaved, cooled, then

214 transferred to an anaerobic chamber (Coy Laboratory Products Inc., Ann Arbor, MI) where 5g of

215 sediment (Zodletone, ZDT), $5 \mathrm{~g}$ of sludge (wastewater treatment plant, WWT), or $5 \mathrm{ml}$ of

216 concentrated lake water (the pellet obtained after centrifugation of $1.5 \mathrm{~L}$ of Grand Lake water

217 (GL)) were added as the inoculum sources. Algal biomass was added as a substrate $(\sim 0.25 \mathrm{~g}$ per

218 bottle). In addition, substrate unamended controls (i.e., ZDT, WWT, and GL enrichments with

219 no algal substrates) were included. After enrichment preparation in the anaerobic chamber, the

220 bottles were stoppered, sealed, taken out of the chamber and the headspace in the bottles was

221 changed by repeated flushing with $100 \% \mathrm{~N}_{2}$. Samples were incubated at room temperature

$222\left(22^{\circ} \mathrm{C}\right)$ in the dark. Enrichments were periodically sampled (at 4, 7, 8, and 10 weeks) for DNA

223 extraction by thoroughly mixing the serum bottle and anoxically withdrawing $3 \mathrm{ml}$ of the

224 enrichment. At the end of the enrichment process (13 weeks for GL, 16 weeks for ZDT and

225 WWT), bottles were sacrificed, centrifuged and $3 \mathrm{ml}$ of the pellet was used for DNA extraction.

226 The rest of the pellet was used for chemical analysis of the remaining algal detritus.

227 DNA extraction, amplification, and sequencing.

228 DNA was extracted using the PowerSoil ${ }^{\circledR}$ DNA Isolation Kit (MO BIO Laboratories, West

229 Carlsbad, CA) as per the manufacturer's instruction. DNA from triplicate treatments was pooled

230 prior to amplification and sequencing. DNA from substrate-unamended controls was also

231 extracted (hereafter pre-enrichment sample). The extracted and pooled DNA ( $\mathrm{n}=30 ; 3$ inoculum

232 sources x 3 algal substrates x 3 time points, plus 3 pre-enrichment samples) was quantified using

233 Qubit fluorometer (Life technologies ${ }^{\circledR}$, Carlsbad, CA). The genes for the V4 hypervariable 
234 region of $16 \mathrm{~S}$ rRNA were amplified using the prokaryotic-specific primer pair 515F and 806R

235 (Wang \& Qian 2009) to avoid amplification of eukaryotic 18S rRNA. Products were sequenced

236 using paired-end Illumina Miseq platform, as previously described (Caporaso et al. 2012). Both

237 PCR amplification and Illumina sequencing were conducted using the services of the Genomic

238 Sequencing and Analysis Facility (GSAF) at the University of Texas at Austin. The sequences

239 are deposited in the SRA database under accession number SRP083898.

240 Data analysis.

241 Sequence processing. mothur software (Schloss et al. 2009) was used for most of the sequence

242 processing and operational taxonomic unit (OTU) assignments. Most of the analyses were

243 conducted on the cowboy server, a high performance super computer housed at the Oklahoma

244 State High Performance Computing Center (http://hpcc.it.okstate.edu). For quality control

245 purposes and to eliminate poor quality sequences, an average quality score of 25 was chosen as

246 the threshold value below which sequences were considered of poor quality and removed from

247 the dataset. In addition, sequences that contained an ambiguous base $(\mathrm{N})$, sequences having a

248 homopolymer stretch longer than 8 bases, and sequences longer than 293 bp were also removed

249 from the datasets.

250 High-quality reads were aligned in mothur using the Silva alignment database as a

251 template. Aligned sequences were then filtered to remove columns that corresponded to '.' or '-'

252 in all sequences. Filtered alignments were then subjected to a pre-clustering de-noising step

253 using a pseudo-single linkage algorithm with the goal of removing sequences that are likely due

254 to sequencing errors (Huse et al. 2010). Possible chimeric sequences were identified and

255 removed using chimera.slayer in mothur. The taxonomy of the remaining sequences was

256 identified according to the Silva taxonomic outline (Release 123, https://www.arb-silva.de/). The 
257 aligned, filtered, de-noised, and chimera-free sequences were used to generate an uncorrected

258 pair wise distance matrix. Sequences were clustered into operational taxonomic units (OTUs) at

$2590.03 \%$ sequence divergence cutoff using the vsearch clustering method employed through

260 mothur. A shared file was created and was used for subsequent analyses. Most of the above steps

261 were derived from the MiSeq SOP available from the mothur website

262 (http://www.mothur.org/wiki/MiSeq_SOP).

263 Criteria used to define lineages contributing to the degradation process. Phyla considered

264 significant to the degradation process were empirically defined as those phyla that constituted

$2655 \%$ or more of the community at any time during enrichment. These include phyla that were

266 abundant prior to enrichment and remained abundant during and after enrichment, phyla that

267 transiently increased in abundance during part of the enrichment but then decreased in

268 abundance by the end of enrichment, and phyla that significantly and progressively increased in

269 abundance with enrichment time. Within these abundant phyla, genera considered significant to

270 the degradation process were also empirically defined as those whose percentage abundance

271 represented $1 \%$ or more of the total abundance.

272 Diversity and community structure comparisons. Various alpha diversity indices (Shannon,

273 Chao, Ace, Good's coverage) were performed on individual datasets in mothur. When

274 comparing species richness across datasets (e.g., number of observed OTUs, species richness

275 estimates using Chao and Ace estimators), numbers were reported per sample size to normalize

276 for the differences in the number of sequences obtained between datasets. Beta diversity based

277 on community structure was assessed by calculating pairwise Bray-Curtis dissimilarity indices

278 and using the output to construct non-metric multidimensional scaling (NMDS) plots in mothur, 
279 Statistical analyses. To study the significance of the effect of inoculum source versus algae type

280 on community structure, we performed an analysis of variance using the function Adonis in the

281 R statistical package vegan. The effect was visualized using the percentage abundances of

282 significant phyla/classes ( $\geq 5 \%$ as defined above) in a constrained correspondence analysis

283 (CCA) using the function cca in the R statistical package vegan.

\section{Quantitative PCR.}

285 We used qPCR to quantify total Bacteria, total Archaea, as well as methanogens and sulfate-

286 reducing bacteria in the enrichments using a MyiQ thermocycler (Bio-Rad Laboratories,

287 Hercules, CA) and SYBR GreenER ${ }^{\mathrm{TM}}$ qPCR SuperMix for iCycler ${ }^{\circledR}$ Instrument (Life

288 Technologies). Primer pair EUB-338F/UNI518R (Fierer et al. 2005) was used to amplify the 16S

289 rRNA genes from the total bacterial community, primer pair A341F/A519R (Qian et al. 2011)

290 was used to amplify 16 S rRNA genes from the total archaeal community, primer pair mlas-

291 ModF/mcrA-R (Angel et al. 2012) was used to amplify the methyl-Coenzyme M reductase

292 ( $m c r A$ ) gene from the total methanogenic community, and primer pair Dsr2060F/Dsr4R (Balk et

293 al. 2015) was used to amplify the dissimilatory sulfite reductase $(d s r B)$ gene from the total

294 sulfate reducing community. The $25-\mu \mathrm{l}$ PCR reaction mixtures contained $0.3 \mu \mathrm{M}$ of each forward

295 and reverse primers (final concentration), $2 \mu \mathrm{l}$ extracted template DNA, and $12.5 \mu \mathrm{l}$ SYBR

296 GreenER ${ }^{\mathrm{TM}}$ qPCR SuperMix. The reactions were heated at $95^{\circ} \mathrm{C}$ for $8.5 \mathrm{~min}$, followed by 40

297 cycles, with one cycle consisting of $30 \mathrm{sec}$ at $95^{\circ} \mathrm{C}, 45 \mathrm{sec}$ at $50^{\circ} \mathrm{C}$ (for total bacteria, total

298 archaea, and methanogens) or $55^{\circ} \mathrm{C}$ (for sulfate reducers), $30 \mathrm{sec}$ at $72^{\circ} \mathrm{C}$, and $15 \mathrm{sec}$ at $85^{\circ} \mathrm{C}$ for

299 signal reading. To calculate the total number of cells belonging to total bacteria, total archaea,

300 methanogens, and sulfate reducers in the enrichments, a standard curve was generated using

301 DNA from Bacillus subtilis strain 168 (ATCC 23857), Haloferax sulfurifontis strain M6 (DSM 
302 16227), Methanosarcina hungatei strain JF1 (ATCC 27890), and Desulfovibrio desulfuricans

303 strain G20 (ATCC BAA-1058), respectively. To account for the multiple copies of 16S rRNA

304 genes per cell, the number of copies obtained from the standard curve was divided by an

305 empirical value of 3.5 (average of 1-6 copies of rRNA genes in one cell). However, since the

$306 m c r A$ and $d s r B$ genes are known to be present as single copies in methanogens, and sulfate

307 reducers, respectively, no such adjustment of the total number of cells was required when

308 calculating the total number of cells belonging to methanogens and sulfate reducers.

309 Chemical analysis of algal detritus.

310 We studied the change in chemical composition of algal detritus during enrichment by

311 quantifying the total soluble carbohydrates, total starch, total protein, and total lipid content of

312 algal biomass pre and post enrichment. Algal detritus was dried overnight at $40^{\circ} \mathrm{C}$ then weighed

313 (DW $_{\mathrm{f}}$; final dry weight) and ground to fine material. The ground material was first used for

314 protein extraction using the method described previously (Rausch 1981). Briefly, algal detritus

315 was extracted $2-3$ times with $0.5 \mathrm{~N} \mathrm{NaOH}$ at $80-100^{\circ} \mathrm{C}$ for 10 minutes followed by cooling and

316 centrifugation to collect the total protein in the supernatant. Total protein extracts were frozen at

$317-20^{\circ} \mathrm{C}$ until assayed using Qubit Protein Assay Kit (Life technologies). The pellet remaining after

318 protein extraction was used for extraction of total soluble carbohydrates and starch. The pellets

319 were first washed 2-3 times with $1 \mathrm{ml}$ acetone to remove pigments. Total soluble carbohydrates

320 were then extracted from the pellet using $80 \%$ ethanol according to the protocol in (Maness

3212010 ) and the total ethanol extract was dried overnight at $40^{\circ} \mathrm{C}$ followed by dissolving the dried

322 extract in water. Total starch remaining in the pellet was extracted by boiling with $1.1 \% \mathrm{HCl}$ for

32330 minutes followed by centrifugation. Total soluble carbohydrates, as well as total starch

324 extracted were quantified using the anthrone method (Maness 2010). The total crude lipids were 
325 extracted from dried algal material with chloroform and quantified with a Nile red assay

326 modified for microplates using the protocol described previously (Higgins et al. 2014). 
328 Sequencing output. A total of 1,007,906 sequences were obtained from all enrichments. After

329 implementation of all quality control criteria described above, 889,230 sequences (88.2\%) were

330 retained for further analysis. The average number of sequences per dataset was 26,946 . The

331 calculated Good's coverage for the majority of samples at putative species $\left(\mathrm{OTU}_{0.03}, 30\right.$ out of 32

332 samples) and family (OTU $\mathrm{O}_{0.10}, 31$ out of 32 samples) levels were always above 96 and $98.2 \%$

333 (average 98.4, and 99.5\%, respectively), strongly indicating that the communities have been

334 adequately sampled in all enrichments (Table S1).

335 Enrichment progress and diversity patterns. Multiple lines of evidence strongly indicate that

336 in all nine treatments, algal detritus degradation occurred and was coupled to an increase in

337 prokaryotic cell numbers and a decrease in alpha diversity both implying enrichment of specific

338 taxa. Visual inspection of all enrichments revealed significant loss of the dried kelp powder, and

339 the algal biomass (Chlorella and Chara) at the conclusion of the experiment. Final time point

340 analysis demonstrated that the majority of the starting dry weight of Chara (86.3, 94.5, and

$34198.0 \%)$, Chlorella (96.0, 98.0, and 99.0\%), and, to a relatively lower extent, kelp (56.7, and 33.6,

$34283.3 \%$ ) in ZDT, WWT, and GL enrichments, respectively, was metabolized at the conclusion of

343 the experiment. Analysis of the chemical composition of the remaining algal detritus in

344 comparison to the starting material showed that the carbohydrate, lipid, and protein contents of

345 the algal detritus were consumed to varying extents (Table 1). Quantitative PCR (qPCR)

346 demonstrated a progressive increase in bacterial 16S rRNA gene copies/ml enrichment in all

347 samples. An increase of 3.5-88.5 fold in total number of bacterial cells was observed by week

348 13-16 in all enrichments and 14.6-2142 fold in the total number of archaeal cells was observed

349 by week 13-16 in 6 out of 9 enrichments (Figure 1). Finally, we followed the change in diversity 
350 estimates in the enrichments datasets as a proxy for enrichment progress. At the end of all

351 enrichments (weeks 13 or 16 ), the number of observed OTUs ${ }_{0.03}$ and $\mathrm{OTUs}_{0.1}$ as well as the

352 estimated species richness (using both Chao and ACE estimators) decreased compared to the

353 pre-enrichment sample, hence indicating the selection for few taxa (Table 2).

354 Microbial community structure analysis. Bray-Curtis dissimilarity indices at $\mathrm{OTU}_{0.03}$ coupled

355 to non-metric multidimensional scaling (NMDS) were used to compare and visualize differences

356 in the microbial community structure between all enrichments at all sampled data points. At first

357 glance, it was apparent that the enriched microbial communities (week 7-10-16 in cases of WWT

358 and ZDT microcosms, or week 4-8-13 in case of GL microcosms) within each algae type-

359 enrichment source combination ( $\mathrm{n}=9$, blue, green, and red shapes in Figure 2) clustered closely

360 together, and were distinct from the pre-enrichment microbial community (black shapes in

361 Figure 2). This observation strongly suggests that the abundant microbial community obtained

362 during the first few weeks of enrichment (week 4 or 7) persisted throughout the enrichment and

363 was responsible for the algal biomass degradation observed at the end of the enrichment (Table

364 1). Analysis of the effect and relative contribution of algae type (Chlorella, Chara, or kelp)

365 versus inoculum source (ZDT, WWT, and GL) on the enriched microbial communities revealed

366 that kelp selects for a distinct and highly similar microbial community, regardless of the

367 inoculum source (ZDT, WWT, and GL) (Figure 2a). On the other hand, within Chlorella and

368 Chara-derived enrichments, the inoculum source, rather than the algae type, appears to be the

369 more important factor in shaping the microbial communities (Figure 2a). This is evident by the

370 presence of three distinct clusters in the NMDS plot corresponding to the three sources of

371 inoculum (ZDT, WWT, and GL) (Figure 2a). 
373

374

375

376

377

378

\section{Table S2.}

392

and the source of inoculum were significant in shaping the microbial community albeit to

varying levels ( $p$-value for algae type $=0.028, p$-value for inoculum source $=0.001$ ). To decipher the relative contributions of algae type versus inoculum source on the microbial community composition at the phylum/class level we employed canonical correspondence analysis (CCA) using the enriched phyla/classes relative abundances. The results (Figure $2 \mathrm{~b}$ ) confirmed the above observation, where the algae type appears to have shaped the microbial community in case of kelp enrichments, while within Chara and Chlorella enrichments, the source of inoculum played a more important role in shaping the community (Figure 2b).

Phylogenetic affiliation of enriched taxa in algal enrichments. In general, a handful of phyla were consistently abundant across all treatments and were considered significant to the algal degradation process (see the criteria we used for defining such phyla in the Materials and Methods section). These phyla were: Firmicutes (in all 9 enrichments), Bacteroidetes (in 6 enrichments), Spirochaetes (in 5 enrichments), and the Gamma (5 enrichments), Delta (6 enrichments), Alpha, Beta, and Epsilon (one enrichment) Proteobacteria (Figure 3-5). However, within this limited number of phyla, the family/genus level enrichment patterns varied widely, suggesting the involvement of a wide range of bacterial lineages in the degradation process. Below, we provide a detailed analysis of the enriched families/genera across various enrichments. The detailed microbial community composition across all datasets is shown in

Chara microcosms. In Chara microcosms, Bacteroidetes, Firmicutes, and Delta-Proteobacteria were consistently abundant (Table 3$)$ and, collectively, constituted the majority $(40.2 \%$ to $72.7 \%$ ) of the community at the end of enrichment. Spirochaetes were abundant only in WWT 
395 and ZDT enrichments, while Gamma-Proteobacteria were abundant only in GL and ZDT 396 enrichments (Figure 3-5).

397 Within the Bacteroidetes, the uncultured putative genus VadinBC27 was consistently

398 enriched (Table 3) regardless of the inoculum source. This uncultured subgroup within the order

399 Bacteroidales has been previously identified as a major lineage in anaerobic digestors (Liu et al.

400 2016; Riviere et al. 2009; Xie et al. 2014; Xu et al. 2012) and was implicated as an anaerobic

401 fermenter of sludge or other carbon sources. Other enriched Bacteroidetes members include the

402 genera Mangroviflexus (ZDT microcosms), previously identified as an important in-situ

403 fermenter of organic matter-rich soil (Ding et al. 2016) and anaerobic cellulolytic microcosms

404 (Gao et al. 2014), Paludibacter (WWT and ZDT microcosms), previously enriched from

405 anaerobic freshwater sediment (Sanchez-Andrea et al. 2013) and shown to be an anaerobic

406 propionate-producer (Qiu et al. 2014; Ueki et al. 2006), Bacteroides (WWT and GL

407 microcosms), a well-documented complex carbohydrate degrader in a wide range of

408 environments (Adamberg et al. 2015; Dongowski et al. 2000; Jiménez et al. 2015), Barnesiella

409 (GL microcosms), a known fermentative gut microbe (Wang et al. 2015), and WCHB1-69 (ZDT

410 microcosms), a yet-uncultured Bacteroidetes family previously encountered in organic solvent-

411 contaminated aquifers and anaerobic digestors (Dojka et al. 1998; Xu et al. 2012) (Table 3,

412 Figure 3-5).

413 Within the Firmicutes, all enriched taxa belonged to the order Clostridiales, a ubiquitous

414 order of strictly anaerobic, fermentative bacteria (Xia et al. 2015). However, the profile of

415 enriched families/genera within this order depended on the inoculum source. Members of

416 Ruminococcaceae were abundant in all microcosms, while members of the families

417 Clostridiaceae_1 and Family XIII were enriched only in ZDT microcosms, and members of the 
418 Lachnospiraceae and Veillonellaceae were enriched only in GL microcosms (Table 3, Figure 3$4195)$.

420 Within the Delta-Proteobacteria, the sulfate-reducing genera Desulfovibrio,

421 Desulfobacter, Desulfobulbous, and Desulfomicrobium were encountered as predominant

422 members in enrichments from some or all inoculum sources. Enrichment of sulfate reducers in

423 ZDT and WWT microcosms was accompanied by a significant decrease in the amount of sulfate 424 in the enrichments (Figure S2). On the other hand, sulfate concentration did not decrease in GL 425 microcosms (Figure S2) in spite of the apparent enrichment of SRBs $(6.9 \%$ of the total enriched 426 taxa). Similar results were previously shown for members of Desulfovibrio and Desulfobulbous 427 in biofilms (Santegoeds et al. 1998), where not all SRBs detected by culture-independent 428 techniques were found to be sulfidogenically active.

429 Members of the Spirochaetes were enriched in WWT and ZDT microcosms. The genus

430 Spirochaeta and the yet uncultured family SHA-4 were identified as the major enriched

431 Spirochaetes members in both enrichments. Both lineages appear to be widely distributed in a

432 wide array of freshwater and marine habitats and enrichments (Bozo-Hurtado et al. 2013; Gu et 433 al. 2004; Leschine et al. 2006; Wang et al. 2014).

434 Members of the Gamma-Proteobacteria were enriched in ZDT and GL microcosms.

435 However, the identity of enriched families/genera differed depending on the inoculum source, 436 where Kluyvera and unclassified Enterobacteriaceae were enriched in ZDT microcosms, while

437 Buttiauxella, Pantoea and Aeromonas were enriched in GL microcosms. All such members are 438 known carbohydrate fermenters previously encountered in microbial consortia degrading plant 439 biomass (Jiménez et al. 2015; Jiménez et al. 2016), in earthworm gut enrichments (Wust et al. 440 2011), and in microbial mats from bicarbonate- and ferrous-iron-rich spring (Hegler et al. 2012). 
441 Chlorella microcosms. Enrichment patterns in Chlorella microcosms were very similar to Chara

442 enrichments; with the phyla Bacteroidetes, Firmicutes, and Delta-Proteobacteria consistently

443 enriched in microcosms derived from all three inoculum sources (ZDT, WWT, and GL),

444 Spirochaetes only enriched in WWT and ZDT microcosms, and Gamma-Proteobacteria enriched

445 in GL (but not ZDT) enrichments. Similar to Chara enrichments, the taxa VadinBC27,

446 Mangroviflexus, Paludibacter, Barnesiella, and WCHB1-69 within the Bacteroidetes;

447 Desulfovibrio, Desulfobacter, and Desulfomicrobium within the Delta Proteobacteria;

448 Spirochaeta and unclassified SHA-4 within the Spirochaetes were all abundant community

449 members at the end of enrichment. Within the Firmicutes, the family Lachnospiraceae was

450 abundant in all enrichments, similar to what was observed in Chara microcosms. However, apart

451 from this notable exception, the enriched community of Firmicutes genera/families differed in

452 Chlorella microcosms when compared to Chara enrichments. Within the ZDT microcosms on

453 Chlorella, a wide range of Clostridiales-affiliated genera and families were encountered, with

454 members of the genera Geosporobacter (family Clostridiaceae_1), and Acidaminobacter (family

455 Clostridiaceae_4), Youngiibacter (family Clostridiaceae_1), and members of Clostridiales

456 Family XIII constituting $\sim 34 \%$ of total sequences encountered in ZDT microcosms. Further, In

457 contrast to Chara enrichments where Veillonellaceae was only restricted to GL microcosms,

458 Chlorella enrichments selected for members of this family in ZDT and WWT microcosms.

459 Chlorella enrichments selected for members of the Gamma-Proteobacteria only in GL

460 microcosms where they constituted $\sim 54 \%$ of the total taxa in these enrichments. Buttiauxella and

461 Aeromonas were identified as major taxa in GL Chlorella microcosms, similar to what was

462 observed in Chara enrichments. In addition, members of the genus Edwardsiella (family

463 Enterobacteriaceae) were identified as a Chlorella enrichment-specific taxon (Figure 3-5, Table 
464 3). Members of the genus Edwardsiella have been repeatedly isolated from marine and

465 freshwater animals and some species have been linked to pathogenesis in fish (Sakazaki 1965).

466 This is consistent with its enrichment in microcosms from a freshwater environment such as

467 Grand Lake.

468 Kelp enrichments. While the microbial communities enriched on Chara and Chlorella exhibited

469 marked similarities regardless of the inoculum source, the community enriched on kelp was quite

470 distinct: In all kelp enrichments, Firmicutes constituted more than $70 \%$ of the total enriched taxa

471 regardless of the inoculum source. In ZDT kelp enrichments, four different Firmicutes taxa were

472 enriched; Clostridium, Anaerosporobacter, Lachnospiraceae-Incertae_Sedis, and Paenibacillus.

473 Anaerosporobacter, a strictly anaerobic spore former, and other Lachnospiraceae members were

474 previously isolated from cellulose and xylan-pectin enrichments of cow feces (Ziemer 2014), and

475 are frequently encountered within the human gut microbiota (Gagen et al. 2015; Lau et al. 2016;

476 Martinez et al. 2013; Nava et al. 2011). Members of the genus Paenibacillus are globally

477 distributed facultative anaerobes ( $\mathrm{Li}$ et al. 2014), some of which are known to exhibit superior

478 plant biomass degradation capacities (Eida et al. 2012). On the other hand, in both GL and WWT

479 kelp microcosms, a single lineage constituted the majority of the enriched Firmicutes; Genus

480 Clostridium in GL, and Family Veillonellaceae in WWT. Members of the genus Clostridium

481 exhibit ubiquitious and global distribution in a wide range of anoxic habitats, while members of

482 the family Veillonellaceae are often encountered in groundwater samples (Mosher et al. 2012),

483 and rice paddy soil (Li et al. 2011).

484 In addition to Firmicutes, ZDT kelp microcosms showed an abundance of the

485 Spirochaetes genus Treponema (20.2\% of the total enriched taxa) previously shown to contribute

486 to the overall cellulolytic activities in barley straw microcosms (Kudo et al. 1987), and WWT 
487 kelp microcosms showed an abundance of members of Epsilon (genera Arcobacter and 488 Sulfurospirilum) and Gamma (genera Tolumonas, Kluyvera, and Acinetobacter) Proteobacteria, 489 collectively comprising $\sim 25 \%$ of the total enriched taxa. Members of these genera were 490 previously implicated in anaerobic plant biomass degradation (Billings et al. 2015; Caldwell et 491 al. 2011; Cardoso et al. 2012). 


\section{Discussion}

493

In this study we investigated the microbial community mediating algal detritus turnover

494

495

496

497

498

499

500

501

502

503

504

505

506

507

508

509

510

511

512

513

514

under anaerobic conditions. We utilized three representative algal species: Chlorella vulgaris strain UTEX2714 representing the Chlorophyta, Chara sp. strain IWP representing the

Charophyceae, and Ascophyllum nodosum (kelp) representing the brown algae (Phaeophyceae).

We followed the turnover of these algae in enrichments that were set up using three different sources of inoculum: an anoxic freshwater sulfide- and sulfur-rich spring (Zodletone spring, OK), a wastewater treatment plant (Municipal wastewater treatment plant in Stillwater, OK), and a seasonally stratified lake that experience seasonal algal blooms (Grand Lake O' the Cherokees, OK). We identified multiple microbial lineages that were significantly enriched in these treatments. Some of these lineages appear to be substrate-specific (i.e. enriched when using a specific algal species as a substrate source regardless of the inoculum source utilized, e.g., VadinBC27 that was enriched on Chara and Chlorella regardless of the inoculum source and Spirochaeta that was enriched on Chara and Chlorella in ZDT and WWT microcosms), habitatspecific (i.e. enriched only when using a specific source of inoculum regardless of the algal substrate utilized, e.g., Buttiauxella, that was enriched in GL microcosms regardless of the algal substrate), or treatment-specific (i.e. encountered only in a specific algal substrate/inoculum source combination, e.g., Arcobacter in WWT microcosms on kelp, Geosporobacter, Acidaminobacter, Anaerosporobacter, and Treponema in ZDT microcosms on kelp, Youngiibacter in ZDT microcosms on Chlorella, and Pantoea in GL microcosms on Chara). Within all nine treatments examined, a high level of diversity was invariably retained at the conclusion of the incubation process. We reason that this is a reflection of the complexity of the substrate utilized. Algal detritus harbors multiple complex macromolecules, e.g., proteins, 
515 lipids, nucleic acids, and polysaccharide, that vary considerably in structure and hence require

516 multiple enzymes and pathways for their efficient degradation (e.g., pectin and cellulose in algal

517 cell walls require an arsenal of degradation enzymes (Abbott \& Boraston 2008; Doi \& Kosugi

518 2004)). Such level of complexity could potentially select for a wide range of organisms, each

519 contributing to the degradation process of a specific substrate within the algal biomass. This is in

520 stark contrast to the selection of one/few microbial lineages in anaerobic incubations conducted

521 using a single, chemically defined substrate (Viggor et al. 2013; Yagi et al. 2010).

522 Our results and subsequent community analysis (Figures 2-5, Table 3) indicate that kelp

523 enriched for a highly similar microbial community that is mostly composed of members of the

524 order Clostridiales; genus Clostridium and Anaerosporobacter and family Veillonellaceae,

525 regardless of the inoculum source (ZDT, WWT, and GL). While only a handful of environments

526 were examined in this study, the consistent selection for members of a specific lineage regardless

527 of the starting inoculum suggests the ecological significance of this lineage in kelp detritus

528 turnover in anaerobic habitats. The reason for this observed pattern of Clostridiales

529 genera/families selection on kelp could only be speculated upon. A possible contributing factor

530 could be the unique cell wall structure of kelp (or brown algae); multiple cellulose microfibrils

531 layers embedded in large interfibrillar matrices that are mostly composed of alginates and fucans

532 (Domozych 2001; Youssef et al. 2015). Alginate (Preiss \& Ashwell 1962a; Preiss \& Ashwell

533 1962b) and fucans (Descamps et al. 2006; Kusaykin et al. 2016) degradation requires highly

534 specific enzymes machineries. Organisms with alginate or fucan/fucoidan-degradation

535 capabilities under aerobic conditions have been previously isolated (Ekborg et al. 2005; Jagtap et

536 al. 2014; Park et al. 2012; Sakai et al. 2004; Thomas et al. 2012; Yonemoto et al. 1993). On the

537 other hand, with the exception of a few studies that used anaerobic batch-fed mixed inocula to 
538 degrade brown algae and produce methane (Moen et al. 1997a; Moen et al. 1997b; Sutherland \&

539 Varela 2014), there is a scarcity of information on the identity of the degrading inocula under

540 anaerobic conditions. In contrast to the number of studies on the anaerobic degradation of other

541 common polysaccharides, e.g., cellulose and xylans, a single study by Kita et al. (Kita et al.

542 2016) reported on the identity of a bacterial consortium (formed mainly of a Clostridiaceae

543 bacterium and a Porphyromonadaceae bacterium (Dysgonomonas capnocytophagoides))

544 anaerobically degrading alginate. Based on the study by Kita et al. (Kita et al. 2016) and the

545 results we report here, it is possible that members of the Clostridiales represent one of very few

546 members possessing alginate and/or fucan-degrading capabilities and that are readily enriched

547 and propagated under laboratory incubations.

548 On the other hand, when using Chara or Chlorella as an algal inoculum, the final

549 microbial community enriched was highly divergent, and the final community structure was

550 mostly dependent on the inoculum sources (ZDT, WWT, GL), rather than the type of algal

551 substrate provided (Figure 2-5, Table 3). While Chlorella and Chara cell walls are quite distinct,

552 they are both similar in being rich in fibrous cellulose and/or hemicellulose with amorphous

553 middle layers composed mainly of pectin (homogalacturonic and rhamnogalacturonic acids

554 polymers) in Charophyta, or sulfated polysaccharides in Chlorophyceae (Domozych 2001;

555 Domozych et al. 2014; Youssef et al. 2015). We reason that the relative similarity of the

556 communities enriched on both types of algae, as well as the enrichment for multiple, rather than

557 a single group of microbial lineages (VadinBC27, Spirochaeta, Lachnospiraceae, Buttauxiella,

558 and Pantoea) is a reflection of the relative ubiquity of microbial lineages capable of the

559 anaerobic degradation of cellulose, hemicellulose, and pectin in the algal cell walls, hence

560 allowing ready access to the intracellular substrates within the algal cells. 
562 required for the effective and complete degradation of complex organic molecules (McInerney et

563 al. 2009; Morris et al. 2013). By examining the known metabolic capabilities of close relatives of

564 lineages enriched in various treatments, one could propose a model depicting their putative

565 involvement in the complex algal detritus degradation processes. In kelp enrichments, complex

566 carbohydrate polymer degradation to monomers could possibly be mediated by various members

567 of the order Clostridiales (Clostridium, Anaerosporobacter, Lachnospiraceae incertae sedis) as

568 shown before (Ziemer 2014), as well as the fermentative bacteria in the Enterobacteriaceae

569 (Kluyvera) (Xin \& He 2013). Produced sugar monomers can be further fermented to various

570 fatty acids (acetate and longer chain fatty acids e.g., butyrate, propionate, etc.) by the same

571 members of the Clostridiales and Enterobacteriaceae, as well as the Epsilon Proteobacterium

572 Sulfurospirillum (Stolz et al. 1999). Proteins in the initial substrate could potentially be degraded

573 by the Epsilon Proteobacterium Arcobacter (Roalkvam et al. 2015). Additionally, while the

574 majority of sequences obtained were bacterial in origin, the few archaeal sequences obtained

575 suggest the enrichment of members of Bathyarchaeota (Table S2). Previous research using

576 genomic sequences of different members of the Bathyarchaeota suggested their involvement in

577 both complex carbohydrates and detrital protein degradation as well as acetate production (Lazar

578 et al. 2016), which could explain their enrichment on kelp. Under anaerobic condition,

579 syntrophic organisms convert the long chain fatty acids produced from the initial polymer

580 degradation to acetate. Definitive identification of syntrophic organisms in culture-independent

581 studies is challenging, given their close phylogenetic affiliation with fermentative lineages

582 (Morris et al. 2013). On the other hand, saccharolytic clostridia members of the family

583 Lachnospiraceae could potentially perform the initial breakdown of polymeric substances and 
584 the fermentation of the resulting sugars to acetate, hydrogen, and CO2 (Krumholz \& Bryant

585 1986). While other obligate syntrophic organisms, e.g. members of the families

586 Syntrophobacteraceae, Syntrophaceae, Syntrophomonadaceae, and Syntrophorhabdaceae, were

587 detected in very low percentage ( $<0.06 \%$ of the total community in any enrichment), their role

588 could not be ruled out. The produced acetate, hydrogen, and $\mathrm{CO}_{2}$ would eventually be converted

589 to methane by methanogens. The role of methanogens as the dominant terminal electron acceptor

590 in kelp enrichment from ZDT and WWT inoculum sources is suggested by the observed increase

591 in mrcA gene copy number in qPCR analysis (Figure 1) and the identification of several

592 sequences affiliated with known methanogens (genera Methanosarcina, Methanothermococcus,

593 Methanogenium, and Methanomicrobium) in kelp enrichment from ZDT (Table S2). The lack of

594 sulfate utilization in all kelp enrichments (Figure S2) argues against the involvement of the SRBs

595 identified in the culture-independent dataset (Desulfovibrio, Desulfobacter, Desulfomicrobium,

596 and Desulfobulbous) and detected by qPCR (Figure 1) in the process. Similar results were

597 previously shown in biofilms (Santegoeds et al. 1998), where not all SRBs detected by culture-

598 independent techniques were found to be sulfidogenically active.

599 Within Chara and Chlorella enrichments, complex carbohydrate (e.g., cellulose, pectin,

600 hemicellulose) degradation to sugar monomers could be mediated by members of the

601 Bacteroidetes uncultured groups VadinBC27 (in all enrichments from all sources) and WCHB1-

60269 (in Chara enrichment from ZDT, and Chlorella enrichment from WWT and GL), as well as

603 the Spirochaetes (Gao et al. 2014) (genus Spirochaeta and the uncultured group SHA-4 enriched

604 on Chara and Chlorella from ZDT and WWT sources). These lineages have been consistently

605 enriched in anaerobic sludge digestors (Godon et al. 1997; Lee et al. 2013), and microcosms with

606 hydrocarbon or halogenated solvents (Dojka et al. 1998; Gu et al. 2004; Xu et al. 2012). 
607 Similarly, members of the Clostridiales [Family Ruminococcaceae (in Chara enrichments from 608 all sources), Family Veillonellaceaea (in Chara enrichments from GL), Family Lachnospiraceae 609 (in Chara and Chlorella enrichments from GL), and Family Clostridiaceae genera Yongiibacter, 610 Geosporobacter, Acidaminobacter (in Chloreela enrichments from ZDT)], as well as

611 Enterobacteriales [Genera Kluyvera (Chara enrichments from ZDT), Pantoea (Chara

612 enrichments from GL), Edwardsiella and Aeromonas (Chlorella enrichment from GL), and

613 Buttiauxella (Chara and Chlorella enrichments from GL)] could potentially mediate complex

614 carbohydrate degradation (Hegler et al. 2012; Jiménez et al. 2015; Jiménez et al. 2016; Sakazaki

615 1965; Wust et al. 2011; Xin \& He 2013; Ziemer 2014). The monomers produced could

616 potentially be converted to long chain volatile fatty acids, acetate, and $\mathrm{H}_{2}$ by the Clostridiales and

617 Enterobacteriales members above. Alternatively, long chain volatile fatty acids could be

618 converted to acetate, $\mathrm{H}_{2}$ and $\mathrm{CO}_{2}$ by syntrophs, or oxidized either completely (to $\mathrm{H}_{2}$ and $\mathrm{CO}_{2}$ ) or

619 incompletely (to acetate, $\mathrm{H}_{2}$ and $\mathrm{CO}_{2}$ ) by sulfate-reducing bacteria [e.g., the complete oxidizers

620 (Desulfobacter in Chara and Chlorella enrichments from ZDT), or the incomplete oxidizers

621 (Desulfovibrio in all Chara and Chlorella enrichments from all sources, Desulfomicrobium in

622 Chara and Chlorella enrichments from ZDT and Chara enrichments from WWT, and

623 Desulfobulbous in Chara enrichment from GL)] when sulfate is available. The produced acetate,

$624 \mathrm{H}_{2}$ and $\mathrm{CO}_{2}$ could either be metabolized to methane by aceticlastic or hydrogenotrophic

625 methanogenic lineages observed in the enrichments (Table S2) (e.g., the aceticlastic

626 Methanosarcina in Chara and Chlorella enrichments from ZDT and WWT, and the

627 hydrogenotrophic Methanothermococcus in Chlorella early (week 7) enrichments from ZDT), or

628 metabolized by the aceticlastic autotrophic SRBs in the presence of sulfate. The increase in $d s r$

629 copy numbers in Chara and Chlorella enrichments as measured by qPCR, the utilization of the 
630 available substrates in these enrichments (loss of sulfate (Figure S2)), as well as the presence of a

631 large and diverse community of SRBs (Table 3, S2) evidenced by the culture-independent

632 analysis, strongly argue for the co-involvement of sulfate reduction and methanogenesis as two

633 competing terminal electron accepting processes in these enrichments. Recently, the

634 methanogenic potential for members of the Bathyarchaeota was suggested based on genomic

635 metabolic reconstruction (Evans et al. 2015). It is worth noting that the Bathyarchaeota phylum

636 was enriched in ZDT Chara and Chlorella microcosms (Table S2) and could potentially be

637 contributing to methanogenesis in these enrichments.

638 In conclusion, our work represents the first systematic survey of microbial communities

639 mediating turnover of algal biomass under anaerobic conditions, and highlights the diversity of

640 lineages putatively involved in the degradation process. The results presented here could

641 certainly open the door for future studies that investigate the interactions between the abundant

642 genera identified as significant for the degradation process, as well as for targeted isolation

643 studies for algal detritus degraders. 


\section{References}

645

646

647

648

649

650

651

652

653

654

655

656

657

658

659

660

661

662

663

664

665

666

667

668

669

670

671

672

673

674

675

676

677

678

679

680

681

682

683

684

685

686

687

Abbott DW, and Boraston AB. 2008. Structural biology of pectin degradation by Enterobacteriaceae. Microbiol Mol Biol Rev 72:301-316.

Adamberg K, Tomson K, Talve T, Pudova K, Puurand M, Visnapuu T, Alamäe T, and Adamberg S. 2015. Levan enhances associated growth of Bacteroides, Escherichia, Streptococcus and Faecalibacterium in fecal microbiota. PLoS ONE 10:e0144042.

Amaral-Zettler L. 2014. Algae. Enc Astrobiol 48:1-2.

Amin SA, Parker MS, and Armbrust EV. 2012. Interactions between Diatoms and Bacteria. Microbiol Mol Biol Rev 76:667-684.

Angel R, Claus P, and Conrad R. 2012. Methanogenic archaea are globally ubiquitous in aerated soils and become active under wet anoxic conditions. ISME J 6:847-862.

Ask J, Karlsson J, Persson L, Ask P, Byström P, and Jansson M. 2009. Whole-lake estimates of carbon flux through algae and bacteria in benthic and pelagic habitats of clear-water lakes. Ecology 90:1923-1932.

Bagatini IL, Eiler A, Bertilsson S, Klaveness D, Tessarolli LP, and Vieira AAH. 2014. Hostspecificity and dynamics in bacterial communities associated with bloom-forming freshwater phytoplankton. PLOS ONE 9:e85950.

Balk M, Keuskamp JA, and Laanbroek HJ. 2015. Potential activity, size, and structure of sulfatereducing microbial communities in an exposed, grazed and a sheltered, non-grazed mangrove stand at the Red Sea Coast. Front Microbiol 6:1478.

Billings AF, Fortney JL, Hazen TC, Simmons B, Davenport KW, Goodwin L, Ivanova N, Kyrpides NC, Mavromatis K, Woyke T, and DeAngelis KM. 2015. Genome sequence and description of the anaerobic lignin-degrading bacterium Tolumonas lignolytica sp. nov. Stand Gen Sci 10:106.

Bohutskyi P, Ketter B, Chow S, Adams KJ, Betenbaugh MJ, Allnutt FCT, and Bouwer EJ. 2015. Anaerobic digestion of lipid-extracted Auxenochlorella protothecoides biomass for methane generation and nutrient recovery. Biores Technol 183:229-239.

Boon AR, Duineveld GCA, Berghuis EM, and van der Weele JA. 1998. Relationships between benthic activity and the annual phytopigment cycle in near-bottom water and sediments in the southern North Sea. Estuar Coast Shelf Sci 46:1-13.

Bozo-Hurtado L, García-Amado MA, Chistoserdov A, Varela R, Narvaez JJ, Colwell R, and Suárez P. 2013. Identification of bacteria in enrichment cultures of sulfate reducers in the Cariaco Basin water column employing Denaturing Gradient Gel Electrophoresis of 16S ribosomal RNA gene fragments. Aquat Biosyst 9:1-11.

Buchan A, LeCleir GR, Gulvik CA, and Gonzalez JM. 2014. Master recyclers: features and functions of bacteria associated with phytoplankton blooms. Nat Rev Microbiol 12:686698.

Buhring SI, Sievert SM, Jonkers HM, Ertefai T, Elshahed MS, Krumholz LR, and Hinrichs KU. 2011. Insights into chemotaxonomic composition and carbon cycling of phototrophic communities in an artesian sulfur-rich spring (Zodletone, Oklahoma, USA), a possible analog for ancient microbial mat systems. Geobiology 9:166-179.

Cai H, Jiang H, Krumholz LR, and Yang Z. 2014. Bacterial community composition of sizefractioned aggregates within the phycosphere of cyanobacterial blooms in a eutrophic freshwater lake. PLoS ONE 9:e102879. 
688

689

690

691

692

693

694

695

696

697

698

699

700

701

702

703

704

705

706

707

708

709

710

711

712

713

714

715

716

717

718

719

720

721

722

723

724

725

726

727

728

729

730

731

Caldwell ME, Allen TD, Lawson PA, and Tanner RS. 2011. Tolumonas osonensis sp. nov., isolated from anoxic freshwater sediment, and emended description of the genus Tolumonas. Int J Syst Evol Microbiol 61:2659-2663.

Cannell RJP. 1990. Algal Biotechnology. Appl Biochem Biotechnol 26:85-105.

Caporaso JG, Lauber CL, Walters WA, Berg-Lyons D, Huntley J, Fierer N, Owens SM, Betley J, Fraser L, Bauer M, Gormley N, Gilbert JA, Smith G, and Knight R. 2012. Ultra-highthroughput microbial community analysis on the Illumina HiSeq and MiSeq platforms. ISME J6:1621-1624.

Cardoso AM, Cavalcante JJV, Cantão ME, Thompson CE, Flatschart RB, Glogauer A, Scapin SMN, Sade YB, Beltrão PJMSI, Gerber AL, Martins OB, Garcia ES, de Souza W, and Vasconcelos ATR. 2012. Metagenomic Analysis of the microbiota from the crop of an invasive snail reveals a rich reservoir of novel genes. PLOS ONE 7:e48505.

Cole JJ. 1982. Interactions between bacteria and algae in aquatic ecosystems. Ann Rev Ecol Syst 13:291-314.

Coveley S, Elshahed MS, and Youssef NH. 2015. Response of the rare biosphere to environmental stressors in a highly diverse ecosystem (Zodletone spring, OK, USA). PeerJ 3:e1182.

Descamps V, Colin S, Lahaye M, Jam M, Richard C, Potin P, Barbeyron T, Yvin J-C, and Kloareg B. 2006. Isolation and culture of a marine bacterium degrading the sulfated fucans from marine brown algae. Mar Biotechnol 8:27-39.

Ding W, Stewart DI, Humphreys PN, Rout SP, and Burke IT. 2016. Role of an organic carbonrich soil and $\mathrm{Fe}(\mathrm{III})$ reduction in reducing the toxicity and environmental mobility of chromium(VI) at a COPR disposal site. Sci Total Environ 541:1191-1199.

Dittami SM, Duboscq-Bidot L, Perennou M, Gobet A, Corre E, Boyen C, and Tonon T. 2016. Host-microbe interactions as a driver of acclimation to salinity gradients in brown algal cultures. ISME J 10:51-63.

Doi RH, and Kosugi A. 2004. Cellulosomes: plant-cell-wall-degrading enzyme complexes. Nat Rev Micro 2:541-551.

Dojka MA, Hugenholtz P, Haack SK, and Pace NR. 1998. Microbial diversity in a hydrocarbonand chlorinated-solvent-contaminated aquifer undergoing intrinsic bioremediation. Appl Environ Microbiol 64:3869-3877.

Domozych DS. 2001. Algal Cell Walls. eLS: John Wiley \& Sons, Ltd.

Domozych DS, Sorensen I, Popper ZA, Ochs J, Andreas A, Fangel JU, Pielach A, Sacks C, Brechka H, Ruisi-Besares P, Willats WG, and Rose JK. 2014. Pectin metabolism and assembly in the cell wall of the charophyte green alga penium margaritaceum. Plant Physiol 165:105-118.

Dongowski G, Lorenz A, and Anger H. 2000. Degradation of pectins with different degrees of esterification by Bacteroides thetaiotaomicron isolated from human gut flora. Appl Environ Microbiol 66:1321-1327.

Durborow RM. 2014. Management of Aquatic Weeds. In: Chauhan BS, and Mahajan G, eds. Recent Advances in Weed Management: Springer, 281-314.

Eida MF, Nagaoka T, Wasaki J, and Kouno K. 2012. Isolation and characterization of cellulosedecomposing bacteria inhabiting sawdust and coffee residue composts. Microb Environ 27:226-233. 
732

733

734

735

736

737

738

739

740

741

742

743

744

745

746

747

748

749

750

751

752

753

754

755

756

757

758

759

760

761

762

763

764

765

766

767

768

769

770

771

772

773

774

775

776
Eigemann F, Hilt S, Salka I, and Grossart HP. 2013. Bacterial community composition associated with freshwater algae: species specificity vs. dependency on environmental conditions and source community. FEMS Microbiol Ecol 83:650-663.

Ekborg NA, Gonzalez JM, Howard MB, Taylor LE, Hutcheson SW, and Weiner RM. 2005. Saccharophagus degradans gen. nov., sp. nov., a versatile marine degrader of complex polysaccharides. Int J Syst Evol Microbiol 55:1545-1549.

Evans PN, Parks DH, Chadwick GL, Robbins SJ, Orphan VJ, Golding SD, and Tyson GW. 2015. Methane metabolism in the archaeal phylum Bathyarchaeota revealed by genomecentric metagenomics. Science 350:434-438.

Fierer N, Jackson JA, Vilgalys R, and Jackson RB. 2005. Assessment of soil microbial community structure by use of taxon-specific quantitative PCR assays. Appl Environ Microbiol 71:4117-4120.

Gagen EJ, Padmanabha J, Denman SE, and McSweeney CS. 2015. Hydrogenotrophic culture enrichment reveals rumen Lachnospiraceae and Ruminococcaceae acetogens and hydrogen-responsive Bacteroidetes from pasture-fed cattle. FEMS Microbiol Lett 362:fnv104.

Gao ZM, Xu X, and Ruan LW. 2014. Enrichment and characterization of an anaerobic cellulolytic microbial consortium SQD-1.1 from mangrove soil. Appl Microbiol Biotechnol 98:465-474.

Gies EA, Konwar KM, Beatty JT, and Hallam SJ. 2014. Illuminating microbial dark matter in meromictic Sakinaw Lake. Appl Environl Microbioll 80:6807-6818.

Godon JJ, Zumstein E, Dabert P, Habouzit F, and Moletta R. 1997. Molecular microbial diversity of an anaerobic digestor as determined by small-subunit rDNA sequence analysis. Appl Environ Microbiol 63:2802-2813.

Gu AZ, Hedlund BP, Staley JT, Strand SE, and Stensel HD. 2004. Analysis and comparison of the microbial community structures of two enrichment cultures capable of reductively dechlorinating TCE and cis-DCE. Environ Microbiol 6:45-54.

Guckert JB, and Cooksey KE. 1990. Triglyceride accumulation and fatty acid profile changes in Chlorella (Chlorophyta) during high $\mathrm{pH}$-induced cell cycle inhibition. J Phycol 26:72-79.

Hallegraeff GM. 1993. A review of harmful algal blooms and their apparent global increase. Phycologia 32:79-99.

Hasegawa Y, Martin JL, Giewat MW, and Rooney-Varga JN. 2007. Microbial community diversity in the phycosphere of natural populations of the toxic alga, Alexandrium fundyense. Environ Microbiol 9:3108-3121.

Hecky RE, and Hesslein RH. 1995. Contributions of benthic algae to lake food webs as revealed by stable isotope analysis. J North Am Benthol Soc 14:631-653.

Hegler F, Lösekann-Behrens T, Hanselmann K, Behrens S, and Kappler A. 2012. Influence of seasonal and geochemical changes on the geomicrobiology of an iron carbonate mineral water spring. Appl Environ Microbiol78:7185-7196.

Higgins BT, Thornton-Dunwoody A, Labavitch JM, and VanderGheynst JS. 2014. Microplate assay for quantitation of neutral lipids in extracts from microalgae. Anal Biochem 465:8189.

Hlavínek P, Stř́teský L, Pešoutová R, and Houdková L. 2016. Biogas production from algal biomass from municipal wastewater treatment. Waste Biomass Valor:1-6.

Hoffmann L. 1989. Algae of terrestrial habitats. Bot Rev 55:77-105. 
777

778

779

780

781

782

783

784

785

786

787

788

789

790

791

792

793

794

795

796

797

798

799

800

801

802

803

804

805

806

807

808

809

810

811

812

813

814

815

816

817

818

819

820
Hoshaw RW, and Mccourt RM. 1988. The Zygnemataceae (Chlorophyta) - a 20-year update of research. Phycologia 27:511-548.

Hu Q, Sommerfeld M, Jarvis E, Ghirardi M, Posewitz M, Seibert M, and Darzins A. 2008. Microalgal triacylglycerols as feedstocks for biofuel production: perspectives and advances. Plant J 54:621-639.

Huse SM, Welch DM, Morrison HG, and Sogin ML. 2010. Ironing out the wrinkles in the rare biosphere through improved OTU clustering. Environ Microbiol 12:1889-1898.

Jagtap SS, Hehemann JH, Polz MF, Lee JK, and Zhao H. 2014. Comparative biochemical characterization of three exolytic oligoalginate lyases from Vibrio splendidus reveals complementary substrate scope, temperature, and $\mathrm{pH}$ adaptations. Appl Environ Microbiol 80:4207-4214.

Jiménez DJ, Chaves-Moreno D, and van Elsas JD. 2015. Unveiling the metabolic potential of two soil-derived microbial consortia selected on wheat straw. Sci Rep 5:13845. 10.1038/srep13845

Jiménez DJ, de Lima Brossi MJ, Schückel J, Kračun SK, Willats WGT, and van Elsas JD. 2016. Characterization of three plant biomass-degrading microbial consortia by metagenomicsand metasecretomics-based approaches. Appl Microbiol Biotechnol:1-15.

Jones AC, Liao TSV, Najar FZ, Roe BA, Hambright KD, and Caron DA. 2013. Seasonality and disturbance: annual pattern and response of the bacterial and microbial eukaryotic assemblages in a freshwater ecosystem. Environ Microbiol 15:2557-2572.

Kita A, Miura T, Kawata S, Yamaguchi T, Okamura Y, Aki T, Matsumura Y, Tajima T, Kato J, Nishio N, and Nakashimada Y. 2016. Bacterial community structure and predicted alginate metabolic pathway in an alginate-degrading bacterial consortium. J Biosci Bioeng 121:286-292.

Krumholz LR, and Bryant MP. 1986. Syntrophococcus sucromutans sp. nov. gen. nov. uses carbohydrates as electron donors and formate, methoxymonobenzenoids or Methanobrevibacter as electron acceptor systems. Arch Microbiol 143:313-318.

Kudo H, Cheng KJ, and Costerton JW. 1987. Interactions between Treponema bryantii and cellulolytic bacteria in the in vitro degradation of straw cellulose. Can J Microbiol 33:244-248.

Kusaykin MI, Silchenko AS, Zakharenko AM, and Zvyagintseva TN. 2016. Fucoidanases. Glycobiology 26:3-12.

Lau JT, Whelan FJ, Herath I, Lee CH, Collins SM, Bercik P, and Surette MG. 2016. Capturing the diversity of the human gut microbiota through culture-enriched molecular profiling. Genome Med 8:72. 10.1186/s13073-016-0327-7

Lazar CS, Baker BJ, Seitz K, Hyde AS, Dick GJ, Hinrichs K-U, and Teske AP. 2016. Genomic evidence for distinct carbon substrate preferences and ecological niches of Bathyarchaeota in estuarine sediments. Environ Microbiol 18:1200-1211.

Lee S-H, Park J-H, Kang H-J, Lee YH, Lee TJ, and Park H-D. 2013. Distribution and abundance of Spirochaetes in full-scale anaerobic digesters. Biores Technol 145:25-32.

Leschine S, Paster BJ, and Canale-Parola E. 2006. Free-living saccharolytic Spirochetes: The genus Spirochaeta. In: Dworkin M, Falkow S, Rodsenberg E, Schleifer K-H, and Stackebrandt E, eds. The Prokaryotes. New York, NY: Springer Science+Business Media, LLC, 195-210. 
821

822

823

824

825

826

827

828

829

830

831

832

833

834

835

836

837

838

839

840

841

842

843

844

845

846

847

848

849

850

851

852

853

854

855

856

857

858

859

860

861

862

863

864

865

866

Li H, Peng J, Weber KA, and Zhu Y. 2011. Phylogenetic diversity of Fe(III)-reducing microorganisms in rice paddy soil: enrichment cultures with different short-chain fatty acids as electron donors. $J$ Soil Sed 11:1234-1242.

Li Y-F, Calley JN, Ebert PJ, and Helmes EB. 2014. Paenibacillus lentus sp. nov., a $\beta$ mannanolytic bacterium isolated from mixed soil samples in a selective enrichment using guar gum as the sole carbon source. Int J Syst Evol Microbiol 64:1166-1172.

Liu C, Li H, Zhang Y, Si D, and Chen Q. 2016. Evolution of microbial community along with increasing solid concentration during high-solids anaerobic digestion of sewage sludge. Biores Technol 216:87-94.

Maness N. 2010. Extraction and analysis of soluble carbohydrates. In: Sunkar R, ed. Plant Stress Tolerance: Methods and Protocols. Totowa, NJ: Humana Press, 341-370.

Mann KH. 1988. Production and use of detritus in various fresh-water, estuarine, and coastal marine ecosystems. Limnol Oceanogr 33:910-930.

Martinez I, Lattimer JM, Hubach KL, Case JA, Yang J, Weber CG, Louk JA, Rose DJ, Kyureghian G, Peterson DA, Haub MD, and Walter J. 2013. Gut microbiome composition is linked to whole grain-induced immunological improvements. ISME J 7:269-280.

McInerney MJ, Sieber JR, and Gunsalus RP. 2009. Syntrophy in anaerobic global carbon cycles. Curr Opin Biotechnol 20:623-632.

Moazami N, Ashori A, Ranjbar R, Tangestani M, Eghtesadi R, and Nejad AS. 2012. Large-scale biodiesel production using microalgae biomass of Nannochloropsis. Biomass Bioenergy 39:449-453.

Moen E, Horn S, and Østgaard K. 1997a. Alginate degradation during anaerobic digestion of Laminaria hyperborea stipes. J Appl Phycol 9:157-166.

Moen E, Horn S, and Østgaard K. 1997b. Biological degradation of Ascophyllum nodosum.J Appl Phycol 9:347-357.

Morris BE, Henneberger R, Huber H, and Moissl-Eichinger C. 2013. Microbial syntrophy: interaction for the common good. FEMS Microbiol Rev 37:384-406.

Mosher JJ, Phelps TJ, Podar M, Hurt RA, Campbell JH, Drake MM, Moberly JG, Schadt CW, Brown SD, Hazen TC, Arkin AP, Palumbo AV, Faybishenko BA, and Elias DA. 2012. Microbial community succession during lactate amendment and electron acceptor limitation reveals a predominance of metal-reducing Pelosinus spp. Appl Environ Microbiol 78:2082-2091.

Mudhoo A. 2012. Biogas production: pretreatment methods in anaerobic digestion. In: Mudhoo A, editor: Wiley.

Muylaert K, Van der Gucht K, Vloemans N, Meester LD, Gillis M, and Vyverman W. 2002. Relationship between bacterial community composition and bottom-up versus top-down variables in four eutrophic shallow lakes. Appl Environ Microbiol 68:4740-4750.

Nabarlatz D-A, Arenas-Beltrán L-P, Herrera-Soracá D-M, and Niño-Bonilla D-A. 2013. Biogas production by anaerobic digestion of wastewater from palm oil mill industry. Ciencia Tecnología y Futuro 5:73-83.

Nava GM, Friedrichsen HJ, and Stappenbeck TS. 2011. Spatial organization of intestinal microbiota in the mouse ascending colon. ISME J 5:627-638.

Omer FKTFAOAT. 2013. Oil and fatty acid composition of spirogyra and chara species from Beastan SWR Spring water in Sulaimani-Kurdistan region of Iraq. Egypt J Exp Biol (Bot) 9:159-162. 
867 Paerl HW, and Otten TG. 2013. Blooms bite the hand that feeds them. Science 342:433-434.

868 Park HH, Kam N, Lee EY, and Kim HS. 2012. Cloning and characterization of a novel

869

870

871 Biotechnol 14:189-202.

872

873

874

875

876

877

878

879

880

881

882

883

884

885

886

887

888

889

890

891

892

893

894

895

896

897

898

899

900

901

902

903

904

905

906

907

908

909

910

911

912

Prabandono K, and Amin S. 2015. Production of biomethane from marine microalgae. In: Kim SK, and Lee CG, eds. Marine Bioenergy: Trends and developments: CRC Press, 303323.

Preiss J, and Ashwell G. 1962a. Alginic acid metabolism in bacteria. I. Enzymatic formation of unsaturated oligosac-charides and 4-deoxy-L-erythro-5-hexoseulose uronic acid. J Biol Chem 237:309-316.

Preiss J, and Ashwell G. 1962b. Alginic acid metabolism in bacteria. II. The enzymatic reduction of 4-deoxy-L-erythro-5-hexoseulose uronic acid to 2-keto-3-deoxy-D-gluconic acid. $J$ Biol Chem 237:317-321.

Qian P-Y, Wang Y, Lee OO, Lau SCK, Yang J, Lafi FF, Al-Suwailem A, and Wong TYH. 2011. Vertical stratification of microbial communities in the Red Sea revealed by 16S rDNA pyrosequencing. ISME J5:507-518.

Qiu YL, Kuang XZ, Shi XS, Yuan XZ, and Guo RB. 2014. Paludibacter jiangxiensis sp. nov., a strictly anaerobic, propionate-producing bacterium isolated from rice paddy field. Arch Microbiol 196:149-155.

Ramaraj R, Unpaprom Y, and Dussadee N. 2016. Potential evaluation of biogas production and upgrading through algae. Int J New Technol Res 2:128-133.

Rausch T. 1981. The estimation of micro-algal protein content and its meaning to the evaluation of algal biomass I. Comparison of methods for extracting protein. Hydrobiologia 78:237251.

Reed DC, Rassweiler A, and Arkema KK. 2008. Biomass rather than growth rate determines variation in net primary production by giant kelp. Ecology 89:2493-2505.

Riviere D, Desvignes V, Pelletier E, Chaussonnerie S, Guermazi S, Weissenbach J, Li T, Camacho P, and Sghir A. 2009. Towards the definition of a core of microorganisms involved in anaerobic digestion of sludge. ISME $J$ 3:700-714.

Roalkvam I, Drønen K, Stokke R, Daae FL, Dahle H, and Steen IH. 2015. Physiological and genomic characterization of Arcobacter anaerophilus IR-1 reveals new metabolic features in Epsilonproteobacteria. Front Microbiol 6:987.

Sakai T, Kawai T, and Kato I. 2004. Isolation and characterization of a fucoidan-degrading marine bacterial strain and its fucoidanase. Mar Biotechnol (NY) 6:335-346.

Sakazaki R. 1965. A proposed group of the family Enterobacteriaceae, the Asakusa group. Int $J$ Syst Evol Microbiol 15:45-47.

Samson R, and Leduy A. 1982. Biogas production from anaerobic-digestion of Spirulinamaxima algal biomass. Biotechnol Bioeng 24:1919-1924.

Sanchez-Andrea I, Stams AJ, Amils R, and Sanz JL. 2013. Enrichment and isolation of acidophilic sulfate-reducing bacteria from Tinto River sediments. Environ Microbiol Rep 5:672-678.

Santegoeds CM, Ferdelman TG, Muyzer G, and de Beer D. 1998. Structural and functional dynamics of sulfate-reducing populations in bacterial biofilms. Appl Environ Microbiol 64:3731-3739.

Sapp M, Wichels A, and Gerdts G. 2007. Impacts of cultivation of marine diatoms on the associated bacterial community. Appl Environ Microbiol 73:3117-3120. 
913 Schloss PD, Westcott SL, Ryabin T, Hall JR, Hartmann M, Hollister EB, Lesniewski RA,

914 Oakley BB, Parks DH, Robinson CJ, Sahl JW, Stres B, Thallinger GG, Van Horn DJ, and

915

916

917

918

919

920

921

922

923

924

925

926

927

928

929

930

931

932

933

934

935

936

937

938

939

940

941

942

943

944

945

946

947

948

949

950

951

952

953

954

955

956

957 Weber CF. 2009. Introducing mothur: open-source, platform-independent, communitysupported software for describing and comparing microbial communities. Appl Environ Microbiol 75:7537-7541.

Sialve B, Bernet N, and Bernard O. 2009. Anaerobic digestion of microalgae as a necessary step to make microalgal biodiesel sustainable. Biotechnol Adv 27:409-416.

Sommer U, Adrian R, De Senerpont Domis L, Elser JJ, Gaedke U, Ibelings B, Jeppesen E, Lürling M, Molinero JC, Mooij WM, van Donk E, and Winder M. 2012. Beyond the Plankton Ecology Group (PEG) model: mechanisms driving plankton succession. Annual Rev Ecol Evol Syst 43:429-448.

Sommer U, Maciej Gliwicz Z, Lampert W, and Duncan A. 1986. The PEG model of seasonal succession of planktonic events in freshwaters. Arch Hydriobiol 106:433-471.

Stolz JF, Ellis DJ, Blum JS, Ahmann D, Lovley DR, and Oremland RS. 1999. Sulfurospirillum barnesii sp. nov. and Sulfurospirillum arsenophilum sp. nov., new members of the Sulfurospirillum clade of the epsilon Proteobacteria. Int J Syst Bacteriol 49 Pt 3:11771180.

Sutherland AD, and Varela JC. 2014. Comparison of various microbial inocula for the efficient anaerobic digestion of Laminaria hyperborea. BMC Biotechnology 14:7-7.

Thomas F, Barbeyron T, Tonon T, Genicot S, Czjzek M, and Michel G. 2012. Characterization of the first alginolytic operons in a marine bacterium: from their emergence in marine Flavobacteriia to their independent transfers to marine Proteobacteria and human gut Bacteroides. Environ Microbiol 14:2379-2394.

Ueki A, Akasaka H, Suzuki D, and Ueki K. 2006. Paludibacter propionicigenes gen. nov., sp. nov., a novel strictly anaerobic, Gram-negative, propionate-producing bacterium isolated from plant residue in irrigated rice-field soil in Japan. Int J Syst Evol Microbiol 56:39-44.

Vanegas CH, and Bartlett J. 2013. Green energy from marine algae: biogas production and composition from the anaerobic digestion of Irish seaweed species. Environ Technol $34: 2277-2283$.

Vanni MJ. 2002. Nutrient cycling by animals in freshwater ecosystems. Ann Rev Ecol Syst 33:341-370.

Vergara-Fernandez A, Vargas G, Alarcon N, and Velasco A. 2008. Evaluation of marine algae as a source of biogas in a two-stage anaerobic reactor system. Biomass Bioenergy 32:338344.

Viggor S, Juhanson J, Jõesaar M, Mitt M, Truu J, Vedler E, and Heinaru A. 2013. Dynamic changes in the structure of microbial communities in Baltic Sea coastal seawater microcosms modified by crude oil, shale oil or diesel fuel. Microbiol Res 168:415-427.

Wang J, Tang H, Zhang C, Zhao Y, Derrien M, Rocher E, van-Hylckama Vlieg JET, Strissel K, Zhao L, Obin M, and Shen J. 2015. Modulation of gut microbiota during probioticmediated attenuation of metabolic syndrome in high fat diet-fed mice. ISME J 9:1-15.

Wang S, Chng KR, Wilm A, Zhao S, Yang K-L, Nagarajan N, and He J. 2014. Genomic characterization of three unique Dehalococcoides that respire on persistent polychlorinated biphenyls. Proc Natl Acad Sci 111:12103-12108.

Wang Y, and Qian P-Y. 2009. Conservative fragments in bacterial 16s rrna genes and primer design for 16s ribosomal DNA amplicons in metagenomic studies. PLoS ONE 4:e7401. 
958

959

960

961

962

963

964

965

966

967

968

969

970

971

972

973

974

975

976

977

978

979

980

981

982

983

984

985

986

987

988

989

990

991

992

993

994

995

996

997

998

999

1000

Ward AJ, Lewis DM, and Green FB. 2014. Anaerobic digestion of algae biomass: A review. Alg Res 5:204-214.

Wetzel R. 2001. Limnology. Lake and river ecosystems. New York, NY: Academic Press.

Wiley PE, Campbell JE, and McKuin B. 2011. Production of biodiesel and biogas from algae: a review of process train options. Water Environ Res 83:326-338.

Wust PK, Horn MA, and Drake HL. 2011. Clostridiaceae and Enterobacteriaceae as active fermenters in earthworm gut content. ISME J 5:92-106.

Xia R, Zhang Y, Critto A, Wu J, Fan J, Zheng Z, and Zhang Y. 2016. The potential impacts of climate change factors on freshwater eutrophication: implications for research and countermeasures of water management in China. Sustainability 8:229.

Xia Y, Chin FYL, Chao Y, and Zhang T. 2015. Phylogeny-structured carbohydrate metabolism across microbiomes collected from different units in wastewater treatment process. Biotechnol Biofuels 8:1-12.

Xie ZF, Wang ZW, Wang QY, Zhu CW, and Wu ZC. 2014. An anaerobic dynamic membrane bioreactor (AnDMBR) for landfill leachate treatment: Performance and microbial community identification. Biores Technol 161:29-39.

Xin F, and He J. 2013. Characterization of a thermostable xylanase from a newly isolated Kluyvera species and its application for biobutanol production. Biores Technol 135:309315.

Xu M, Chen X, Qiu M, Zeng X, Xu J, Deng D, Sun G, Li X, and Guo J. 2012. Bar-Coded Pyrosequencing reveals the responses of PBDE-degrading microbial communities to electron donor amendments. PLOS ONE 7:e30439.

Yagi JM, Suflita JM, Gieg LM, DeRito CM, Jeon C-O, and Madsen EL. 2010. Subsurface cycling of nitrogen and anaerobic aromatic hydrocarbon biodegradation revealed by nucleic acid and metabolic biomarkers. Appl Environ Microbiol 76:3124-3134.

Yen HW, and Brune DE. 2007. Anaerobic co-digestion of algal sludge and waste paper to produce methane. Biores Technol 98:130-134.

Yonemoto Y, Tanaka H, Hisano T, Sakaguchi K, Abe S, Yamashita T, Kimura A, and Murata K. 1993. Bacterial alginate lyase gene: Nucleotide sequence and molecular route for generation of alginate lyase species. J Ferm Bioeng 75:336-342.

Youssef NH, Couger MB, and Elshahed MS. 2010. Fine-scale bacterial beta diversity within a complex ecosystem (Zodletone Spring, OK, USA): the role of the rare biosphere. PLoS ONE 5:e12414.

Youssef NH, Farag IF, Rinke C, Hallam SJ, Woyke T, and Elshahed MS. 2015. In silico analysis of the metabolic potential and niche specialization of candidate phylum "Latescibacteria" (WS3). PLoS One 10:e127499

Yuan XZ, Shi XS, Zhang DL, Qiu YL, Guo RB, and Wang LS. 2011. Biogas production and microcystin biodegradation in anaerobic digestion of blue algae. Energy Environ Sci 4:1511-1515.

Ziemer CJ. 2014. Newly cultured bacteria with broad diversity isolated from eight-week continuous culture enrichments of cow feces on complex polysaccharides. Appl Environ Microbiol 80:574-585. 


\section{Figure legends}

1002 Figure 1. Total number of bacterial, archaeal, sulfate-reducing, and methanogenic cells in the

1003 pre-enrichment sample (O) versus post-enrichment samples at week 4 for GL enrichments or

1004 week 7 for ZDT and WWT enrichment ( $\square$ ), post-enrichment samples at week 8 for GL

1005 enrichments or week 10 for ZDT and WWT enrichment $(\square)$, and post-enrichment samples at

1006 week 13 for GL enrichments or week 16 for ZDT and WWT enrichment ( $\square$ ) as measured by

1007 quantitative PCR. The enrichment inoculum source is shown on the left, while the algae type

1008 used is shown on top. Error bars are averages \pm standard deviations from three biological

1009 replicates. Linear regression analysis was performed to examine the trend of increase in cell

1010 numbers with the weeks of enrichment, and the significance of such trend was tested by

1011 calculating the P-values of the F-statistics obtained, where "**" denotes significant P-value $<$

10120.05, “*” denotes p-value $>0.05$ but $<0.1$, "NS" denotes non-significant P-value $>0.1$, and

1013 "ND" refers to cases where the linear regression analysis was not performed because two or

1014 more samples were below the detection level of the qPCR. In the few cases, denoted by a

1015 superscript letter a, where the total cell numbers increased initially then decreased by the last

1016 week of enrichment, the linear regression was only carried on total numbers from the first three

1017 weeks of enrichments.

1018 Figure 2. Microbial community structure analysis in the enrichment microcosms $(n=26)$ as

1019 compared to the pre-enrichment inoculum sources $(n=3)$. The inoculum sources are denoted by

1020 shapes; ZDT (\$), WWT (1), and GL (O), and the algae types are denoted by color; Chara

1021 (blue), Chlorella (green), Kelp (red), and no algae, i.e. pre-enrichment community, (black). Each

1022 enrichment condition (inoculum source $\mathrm{x}$ algae type) is represented by 3 sample points

1023 corresponding to the weeks during enrichment, except for GL-kelp enrichment where the dataset 
1024 from week 4 is not shown due to the small number of sequences obtained with this dataset. (A)

1025 Non-metric multidimensional scaling plots based on Bray-Curtis dissimilarity indices at the

1026 species level (0.03). For Chara and Chlorella enrichments, communities grouped by the

1027 inoculum source, while Kelp enrichments grouped by the algae type. (B) Canonical

1028 correspondence analysis using the abundant phyla/classes relative abundances to study the effect

1029 of algae type and inoculum source on the microbial community composition. Here, the same

1030 pattern is observed at the phylum/class level, where the community structure of Chara and

1031 Chlorella enrichments were similar and grouped by inoculum source, while the microbial

1032 community of Kelp enrichments were quite distinct and grouped together regardless of the

1033 inoculum source. This pattern is reflected on the direction of the factors arrows, where the algae

1034 type is pointing in the direction of the Kelp enrichments. The CCA also depicts the abundant

1035 phyla/classes that seem to shape the microbial community in the different enrichments; Gamma-

1036 Proteobacteria in GL Chara and Chlorella enrichments, Spirochaetes and Firmicutes in ZDT-

1037 Chlorella enrichment, Delta-Proteobacteria and Bacteroidetes in ZDT-Chara enrichments and

1038 WWT Chara and Chlorella enrichments, and Epsilon-Proteobacteria and Firmicutes in Kelp

1039 enrichments regardless of the inoculum source. The constrained variables explained $57 \%$ of the

1040 variance.

1041 Figure 3. Microbial community composition in ZDT enrichments. Abundant phyla/classes are

1042 shown as area charts for Chara (i), Chlorella (ii), and Kelp (iii) enrichments for each inoculum

1043 source. Phyla that constituted $5 \%$ or more of the community at any time during enrichment were

1044 considered significant to the degradation process and are shown in the area charts. These include

1045 phyla that were abundant prior to enrichment and remained abundant during and after

1046 enrichment [e.g., Bacteroidetes in Chara and Chlorella enrichments (i, ii)], and phyla that 
1047 significantly and progressively increased in abundance with enrichment time [e.g., Firmicutes in

1048 Kelp enrichments (iii)]. Bar charts depict the relative abundance of abundant genera (>1\%) in

1049 each of the abundant phyla/classes shown in i-ii-iii. These include Proteobacteria (iv),

1050 Bacteroidetes (v), Firmicutes (vi), and Spirochaetes (vii). The X-axis denotes the weeks of

1051 enrichment (i-iii), or the weeks of enrichment and algae type (iv-vii). " 0 " denotes the community

1052 composition in the pre-enrichment inoculum source.

1053 Figure 4. Microbial community composition in WWT enrichments. Abundant phyla/classes are

1054 shown as area charts for Chara (i), Chlorella (ii), and Kelp (iii) enrichments for each inoculum

1055 source. Phyla that constituted $5 \%$ or more of the community at any time during enrichment were

1056 considered significant to the degradation process and are shown in the area charts. These include

1057 phyla that were abundant prior to enrichment and remained abundant during and after

1058 enrichment [e.g., Bacteroidetes in Chara and Chlorella enrichments (i, ii), phyla that transiently

1059 increased in abundance during part of the enrichment but then decreased in abundance by the end

1060 of enrichment [e.g., Delta-Proteobacteria in Chara and Chlorella enrichments (i, ii)], and phyla

1061 that significantly and progressively increased in abundance with enrichment time [e.g.,

1062 Firmicutes in Kelp enrichments (iii)]. Bar charts depict the relative abundance of abundant

1063 genera $(>1 \%)$ in each of the abundant phyla/classes shown in i-ii-iii. These include

1064 Proteobacteria (iv), Firmicutes (v), Bacteroidetes (vi), and Spirochaetes (vii). The X-axis denotes

1065 the weeks of enrichment (i-iii), or the weeks of enrichment and algae type (iv-vii). "0" denotes

1066 the community composition in the pre-enrichment inoculum source.

1067 Figure 5. Microbial community composition in GL enrichments. Abundant phyla/classes are

1068 shown as area charts for Chara (i), Chlorella (ii), and Kelp (iii) enrichments for each inoculum

1069 source. Phyla that constituted $5 \%$ or more of the community at any time during enrichment were 
1070 considered significant to the degradation process and are shown in the area charts. These include

1071 phyla that were abundant prior to enrichment and remained abundant during and after

1072 enrichment [Gamma-Proteobacteria in Chara and Chlorella enrichments (i, ii)], and phyla that

1073 significantly and progressively increased in abundance with enrichment time [e.g., Firmicutes in

1074 Kelp enrichments (iii)]. Bar charts depict the relative abundance of abundant genera $(>1 \%)$ in

1075 each of the abundant phyla/classes shown in i-ii-iii. These include Bacteroidetes (iv), Firmicutes

1076 (v), Delta and Epsilon-Proteobacteria (vi), Gamma-Proteobacteria (vii), Alpha and Beta

1077 Proteobacteria (viii), and Planctomycetes (ix). The X-axis denotes the weeks of enrichment (i-

1078 iii), or the weeks of enrichment and algae type (iv-ix). " 0 " denotes the community composition

1079 in the pre-enrichment inoculum source.

1080

1081

1082

1083

1084

1085

1086

1087

1088

1089

1090

1091

1092

1093

1094 
1095 Tables

1096 Table 1. Percentage of various algal components consumed under different enrichment

1097 conditions $^{\mathrm{a}}$

\begin{tabular}{|l|l|l|l|l|l|l|l|l|l|}
\hline \multirow{2}{*}{$\begin{array}{l}\text { Algal Detritus } \\
\text { components }\end{array}$} & \multicolumn{3}{|l|}{ ZDT enrichment } & \multicolumn{3}{l|}{ WWT enrichment } & \multicolumn{3}{l|}{ GL enrichment } \\
\cline { 2 - 12 } & Chara & Chlorella & Kelp & Chara & Chlorella & Kelp & Chara & Chlorella & Kelp \\
\hline Carbohydrate & 87 & 96.5 & 52.9 & 99.7 & 98 & 15.7 & 98.3 & 99.2 & 86.2 \\
\hline Protein & 72 & 92.9 & 60 & 94 & 96.9 & 70 & 96 & 97.6 & 82 \\
\hline Lipid & 100 & NA $^{\mathrm{b}}$ & 71 & 62.5 & NA $^{\mathrm{b}}$ & 70 & 96 & $\mathrm{NA}^{\mathrm{b}}$ & 86 \\
\hline$\%$ Biomass lost & 86.3 & 96 & 56.7 & 94.5 & 98 & 33.6 & 98 & 99 & 83.3 \\
\hline
\end{tabular}

1098

a: Carbohydrate, protein, and lipid contents of algal detritus were determined before

1099 and after enrichment. Percentages are calculated based on the dry weight at $\mathrm{T}_{\mathrm{f}}$.

1100 Original algal detritus composition was as follows (\%Carbohydrate: \%Protein:

1101 \%Lipid): Chara, 88:6.5:5.5; Chlorella, 86.7:13.3:0; Kelp, 67.9:14.1:18.

1102 b: Lipids in Chlorella biomass were BDL

1103 c: Based on dry weight remaining at the end of enrichment $\left(\mathrm{DW}_{\mathrm{f}}\right)$, and the initial dry weight used

1104 for enrichment $\left(\mathrm{DW}_{0}\right)$ using the equation: \% biomass loss $=\left(\mathrm{DW}_{0^{-}}-\mathrm{DW}_{\mathrm{f}}\right) / \mathrm{DW}_{0} \times 100$. Initial dry

1105 weight for kelp was equivalent to the weight added to each enrichment bottle since it was in dry

1106 powder form. However, initial dry weight for Chara and Chlorella was determined by

1107 incubating an amount equivalent to the wet weight added to each enrichment bottle overnight at

$110840^{\circ} \mathrm{C}$ then weighing its dry weight following moisture loss.

1109

1110

1111

1112

1113

1114

1115

1116

1117

1118

1119

1120

1121

1122

1123

1124

1125

1126

1127

1128

1129

1130

1131

1132 
1133 Table 2. Number of OTUs ${ }_{0.03}$ and OTUs ${ }_{0.1}$ normalized to the total number of sequences, and the 1134 estimated species richness (using both Chao and ACE estimators) normalized to the total number 1135 of sequences

\begin{tabular}{|c|c|c|c|c|c|c|c|c|c|c|}
\hline \multirow{2}{*}{$\begin{array}{c}\text { Source } \\
\text { cutoff }^{\mathrm{a}}\end{array}$} & \multirow{2}{*}{$\begin{array}{l}\text { Weeks of } \\
\text { enrichment }\end{array}$} & \multicolumn{3}{|c|}{ Chara } & \multicolumn{3}{|c|}{ Chlorella } & \multicolumn{3}{|c|}{ Kelp } \\
\hline & & OTUs & Chao & $\mathrm{ACE}$ & OTUs & Chao & $\mathrm{ACE}$ & OTUs & Chao & $\mathrm{ACE}$ \\
\hline \multirow{4}{*}{ ZDT_0.03 } & 0 & 0.193 & 0.373 & 0.501 & 0.193 & 0.373 & 0.501 & 0.193 & 0.373 & 0.501 \\
\hline & 7 & 0.021 & 0.040 & 0.056 & 0.031 & 0.054 & 0.067 & 0.060 & 0.130 & 0.255 \\
\hline & 10 & 0.030 & 0.051 & 0.068 & 0.022 & 0.043 & 0.058 & 0.069 & 0.148 & 0.265 \\
\hline & 16 & 0.028 & 0.059 & 0.078 & 0.025 & 0.051 & 0.069 & 0.046 & 0.118 & 0.208 \\
\hline \multirow[t]{4}{*}{ ZDT_0.1 } & 0 & 0.051 & 0.078 & 0.088 & 0.051 & 0.078 & 0.088 & 0.051 & 0.078 & 0.088 \\
\hline & 7 & 0.008 & 0.011 & 0.010 & 0.016 & 0.023 & 0.028 & 0.026 & 0.043 & 0.058 \\
\hline & 10 & 0.012 & 0.017 & 0.016 & 0.009 & 0.013 & 0.015 & 0.026 & 0.042 & 0.053 \\
\hline & 16 & 0.011 & 0.016 & 0.019 & 0.009 & 0.012 & 0.014 & 0.019 & 0.029 & 0.040 \\
\hline \multirow[t]{4}{*}{ GL_0.03 } & 0 & 0.043 & 0.091 & 0.140 & 0.043 & 0.091 & 0.140 & 0.043 & 0.091 & 0.140 \\
\hline & 4 & 0.008 & 0.019 & 0.033 & 0.014 & 0.025 & 0.035 & ND & ND & ND \\
\hline & 7 & 0.014 & 0.032 & 0.044 & 0.010 & 0.020 & 0.024 & 0.092 & 0.116 & 0.123 \\
\hline & 13 & 0.022 & 0.055 & 0.057 & 0.011 & 0.018 & 0.029 & 0.036 & 0.063 & 0.076 \\
\hline \multirow[t]{4}{*}{ GL_0.1 } & 0 & 0.020 & 0.032 & 0.042 & 0.020 & 0.032 & 0.042 & 0.020 & 0.032 & 0.042 \\
\hline & 4 & 0.003 & 0.007 & 0.009 & 0.008 & 0.015 & 0.022 & ND & ND & ND \\
\hline & 7 & 0.006 & 0.015 & 0.020 & 0.005 & 0.009 & 0.010 & 0.051 & 0.058 & 0.061 \\
\hline & 13 & 0.010 & 0.015 & 0.014 & 0.005 & 0.007 & 0.008 & 0.017 & 0.026 & 0.029 \\
\hline \multirow[t]{4}{*}{ WWT_0.03 } & 0 & 0.048 & 0.087 & 0.108 & 0.048 & 0.087 & 0.108 & 0.048 & 0.087 & 0.108 \\
\hline & 7 & 0.043 & 0.072 & 0.092 & 0.066 & 0.109 & 0.140 & 0.013 & 0.039 & 0.055 \\
\hline & 10 & 0.020 & 0.036 & 0.046 & 0.033 & 0.052 & 0.061 & 0.020 & 0.043 & 0.064 \\
\hline & 16 & 0.030 & 0.051 & 0.068 & 0.021 & 0.036 & 0.043 & 0.012 & 0.025 & 0.035 \\
\hline \multirow[t]{4}{*}{ WWT_0.1 } & 0 & 0.013 & 0.022 & 0.029 & 0.013 & 0.022 & 0.029 & 0.013 & 0.022 & 0.029 \\
\hline & 7 & 0.018 & 0.025 & 0.024 & 0.030 & 0.043 & 0.048 & 0.006 & 0.009 & 0.012 \\
\hline & 10 & 0.006 & 0.009 & 0.009 & 0.013 & 0.019 & 0.019 & 0.006 & 0.010 & 0.014 \\
\hline & 16 & 0.011 & 0.015 & 0.017 & 0.008 & 0.010 & 0.010 & 0.004 & 0.007 & 0.009 \\
\hline
\end{tabular}

1136

1137

1138

1139

1140

1141

1142

1143

1144

1145

1146

1147

a: Source refers to the inoculum source, while cutoff refers to the percentage divergence cutoff used to assign sequences into operational taxonomic units (OTUs). For each inoculum source, the numbers are shown for OTUs at the putative species level $(0.03)$ and the putative order level (0.1).

ND: not determined due to the small number of sequences obtained for this dataset. 
1148 Table 3. Abundant lineages $(>1 \%)$ within the abundant/enriched phyla shown in Figure 3-5. \begin{tabular}{|l|l|l|l|l|l}
\hline Phylum/ Class & Class/ Order & Family-genus & WWT & ZDT & GL \\
\hline
\end{tabular}

\section{Chara enrichments}

\begin{tabular}{|c|c|c|c|c|c|}
\hline \multirow[t]{7}{*}{ Bacteroidetes } & \multirow[t]{5}{*}{ Bacteroidales } & Marinilabiaceaea-Mangroviflexus & 0.58 & 4.16 & 0 \\
\hline & & Porphyromonadaceae-Paludibacter & 1.47 & 1 & 0.1 \\
\hline & & Porphyromonadaceae-Bacteroides & 2.11 & 0.05 & 6.91 \\
\hline & & Porphyromonadaceae-Barnesiella & 0 & 0 & 1.58 \\
\hline & & Rikenellacea-VadinBC27 & 6.1 & 11.45 & 2.78 \\
\hline & Sphingobacteriales & WCHB1-69-unclassified & 0.76 & 3.73 & 0.84 \\
\hline & \multicolumn{2}{|c|}{ Unclassified Bacteroidetes } & 14.34 & 4.03 & 0 \\
\hline \multirow[t]{10}{*}{ Firmicutes } & \multirow[t]{9}{*}{ Clostridiales } & Clostridiaceae_1-Youngiibacter & 0.003 & 1.36 & 0 \\
\hline & & Family XIII & 0.41 & 1.85 & 0.1 \\
\hline & & Ruminococcaceae_Incertae_Sedis & 0.07 & 0.09 & 1.61 \\
\hline & & Ruminococcaceae-Ruminococcus & 0.02 & 0.03 & 2.38 \\
\hline & & Other Ruminococcaceae & 3.62 & 1.47 & 0 \\
\hline & & Lachnospiraceae_Incertae_Sedis & 0.16 & 0.45 & 6.87 \\
\hline & & $\begin{array}{l}\text { Lachnospiraceae-Parasporobacterium- } \\
\text { Sporobacterium }\end{array}$ & 0 & 0.04 & 2.51 \\
\hline & & Veillonellaceae-uncultured & 0 & 0 & 3.1 \\
\hline & & Unclassified Clostridiales & 3.75 & 3.4 & 0.07 \\
\hline & \multicolumn{2}{|c|}{ Unclassified Firmicutes } & 0.69 & 8.02 & 0 \\
\hline \multirow[t]{3}{*}{ Spirochaetes } & \multirow[t]{2}{*}{ Spirochaetales } & Spirochaetaceae-Spirochaeta & 10.67 & 4.69 & 0 \\
\hline & & SHA-4-unclassified & 2.92 & 2.48 & 0 \\
\hline & \multicolumn{2}{|l|}{ Unclassified } & 6.91 & 0.29 & 0 \\
\hline \multirow{4}{*}{$\begin{array}{l}\text { Delta } \\
\text { Proteobacteria }\end{array}$} & \multirow[t]{2}{*}{ Desulfobacterales } & Desulfobacteriaceae-Desulfobacter & 0.36 & 1.39 & 0 \\
\hline & & Desulfobulbaceae-Desulfobulbous & 0.28 & 0.69 & 1.22 \\
\hline & \multirow[t]{2}{*}{ Desulfovibrionales } & Desulfovibrionacea-Desulfovibrio & 5.69 & 1.42 & 5.67 \\
\hline & & Desulfovibrionaceae-Desulfomicrobium & 1.89 & 5.69 & 0 \\
\hline \multirow{5}{*}{$\begin{array}{l}\text { Gamma } \\
\text { Proteobacteria }\end{array}$} & \multirow[t]{4}{*}{ Enterobacteriales } & Enterobacteriaceae-Kluyvera & 0 & 4.15 & 0.04 \\
\hline & & Enterobacteriaceae-unclassified & 0 & 4.2 & 0 \\
\hline & & Enterobacteriaceae-Buttiauxella & 0 & 0 & 44.1 \\
\hline & & Enterobacteriaceae-Pantoea & 0 & 0 & 11 \\
\hline & Aeromonadales & Aeromonadaceae-Aeromonas & 0 & 0.11 & 1.87 \\
\hline \multicolumn{6}{|c|}{ Chlorella enrichments } \\
\hline \multirow[t]{4}{*}{ Bacteroidetes } & \multirow[t]{4}{*}{ Bacteroidales } & Marinilabiaceaea-Mangroviflexus & 0.16 & 2.27 & 0 \\
\hline & & Porphyromonadaceae-Paludibacter & 2.59 & 0.46 & 0.81 \\
\hline & & Porphyromonadaceae-Barnesiella & 0.002 & 0 & 1.7 \\
\hline & & Rikenellacea-VadinBC27 & 16.18 & 9.11 & 1.95 \\
\hline
\end{tabular}




\begin{tabular}{|c|c|c|c|c|c|}
\hline & & Other & 1.78 & 0.2 & 2.95 \\
\hline & Sphingobacteriales & WCHB1-69-unclassified & 2.14 & 0.64 & 5.18 \\
\hline & \multicolumn{2}{|c|}{ Unclassified Bacteroidetes } & 2.69 & 1.18 & 0 \\
\hline \multirow[t]{8}{*}{ Firmicutes } & \multirow{7}{*}{\begin{tabular}{|l|} 
Clostridia/ \\
Clostridiales
\end{tabular}} & Clostridiaceae 1-Youngiibacter & 0.006 & 8.94 & 0 \\
\hline & & Clostridiaceae 4-Geosporobacter & 0 & 11.44 & 0 \\
\hline & & Family_XII-Acidaminobacter & 0 & 3.77 & 0 \\
\hline & & Family XIII & 0.67 & 6.32 & 0.02 \\
\hline & & Lachnospiraceae_Incertae_Sedis & 0.03 & 0.06 & 7.63 \\
\hline & & Veillonellaceae-uncultured & 1.56 & 1.69 & 0.94 \\
\hline & & Unclassified Clostridiales & 1.78 & 2.44 & 0 \\
\hline & \multicolumn{2}{|c|}{ Unclassified Firmicutes } & 0.82 & 4.87 & 0 \\
\hline \multirow[t]{3}{*}{ Spirochaetes } & \multirow[t]{2}{*}{ Spirochaetales } & Spirochaetaceae-Spirochaeta & 21.65 & 2.62 & 0 \\
\hline & & SHA-4-unclassified & 5.87 & 2.35 & 0 \\
\hline & \multicolumn{2}{|l|}{ Unclassified } & 0.3 & 0.86 & 0 \\
\hline \multirow{3}{*}{$\begin{array}{l}\text { Delta } \\
\text { Proteobacteria }\end{array}$} & Desulfobacterales & Desulfobacteriaceae-Desulfobacter & 0.03 & 7.31 & 0 \\
\hline & \multirow[t]{2}{*}{ Desulfovibrionales } & Desulfovibrionacea-Desulfovibrio & 2.93 & 1.18 & 21.38 \\
\hline & & Desulfovibrionaceae-Desulfomicrobium & 0.7 & 6.38 & 0 \\
\hline \multirow{3}{*}{$\begin{array}{l}\text { Gamma } \\
\text { Proteobacteria }\end{array}$} & \multirow[t]{2}{*}{ Enterobacteriales } & Enterobacteriaceae-Buttiauxella & 0 & 0 & 37.75 \\
\hline & & Enterobacteriaceae-Edwardsiella & 0 & 0 & 7.64 \\
\hline & Aeromonadales & Aeromonadaceae-Aeromonas & 0 & 0 & 8.14 \\
\hline \multicolumn{6}{|c|}{ Kelp enrichments } \\
\hline \multirow{2}{*}{$\begin{array}{l}\text { Epsilon } \\
\text { Proteobacteria }\end{array}$} & \multirow[t]{2}{*}{ Campylobacterales } & Campylobacteraceae-Arcobacter & 8.54 & 0.01 & 0 \\
\hline & & Campylobacteraceae-Sulfurospirillum & 2.19 & 0.05 & 0.007 \\
\hline \multirow{5}{*}{$\begin{array}{l}\text { Gamma } \\
\text { Proteobacteria }\end{array}$} & Aeromonadales & Aeromondaceae-Tolumonas & 5.37 & 0.002 & 0 \\
\hline & \multirow[t]{2}{*}{ Enterobacterales } & Enterobacteriaceae-Kluyvera & 2.95 & 0.006 & 0 \\
\hline & & Enterobacteriaceae-unclassified & 1.71 & 0 & 0 \\
\hline & Pseudomonadales & Moraxellaceae-Acinetobacter & 2.41 & 0 & 0.91 \\
\hline & \multicolumn{2}{|l|}{ other } & 2 & 0.992 & 5.09 \\
\hline \multirow[t]{5}{*}{ Firmicutes } & \multirow[t]{4}{*}{ Clostridiales } & Clostridiaceae-Clostridium & 0.49 & 29.55 & 77.73 \\
\hline & & Lachnospiraceae-Incertae_Sedis & 0.02 & 19.56 & 0.68 \\
\hline & & Lachnospiraceae-Anaerosporobacter & 0.004 & 8.1 & 0 \\
\hline & & Veillonellaceae-unclassified & 65.89 & 0.01 & 0 \\
\hline & Bacillales & Paenibacillaceae-Paenibacillus & 0 & 2.1 & 0 \\
\hline
\end{tabular}


1152 Figures.

1153 Figure 1.

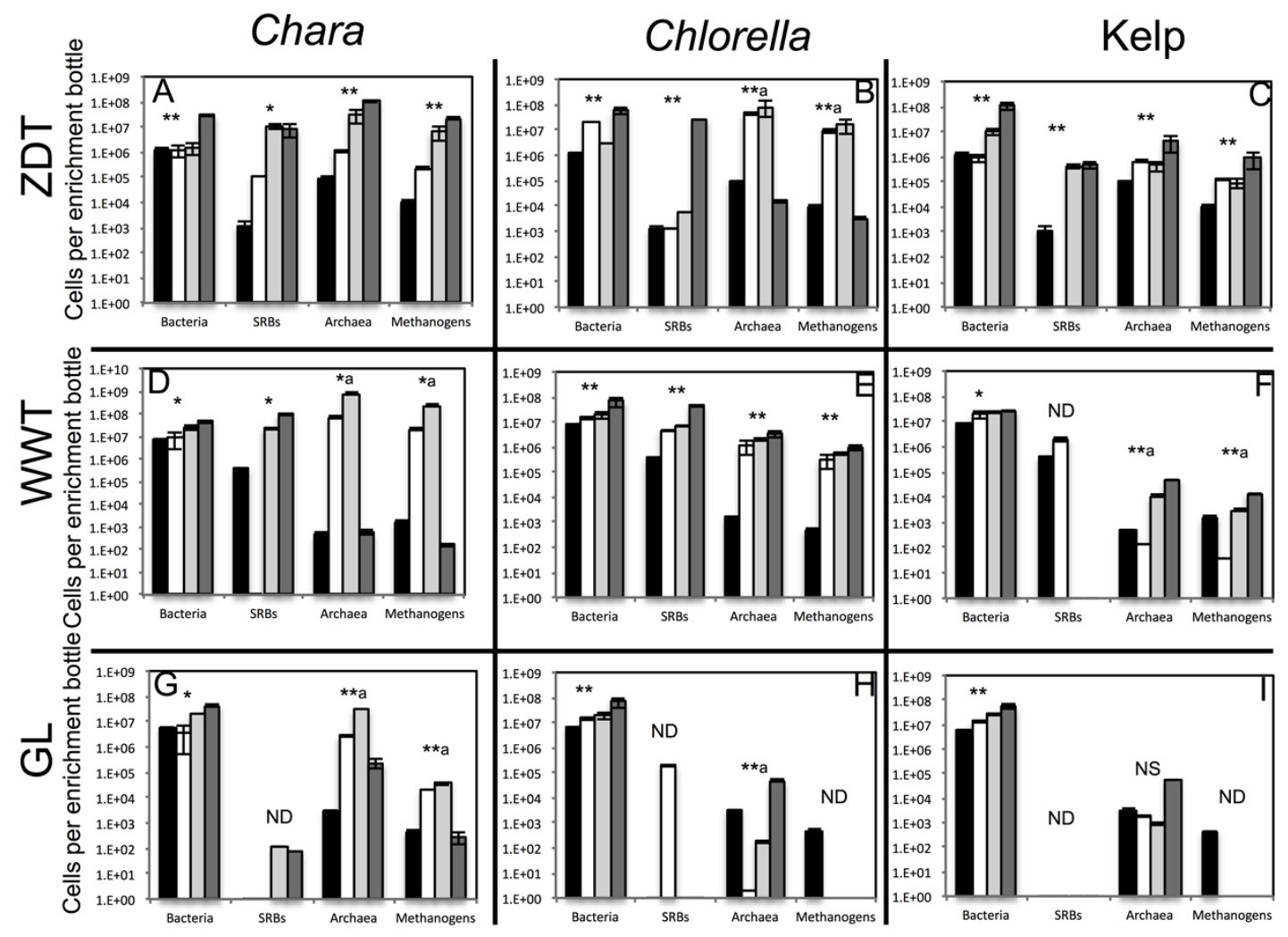

1154

1155

1156

1157

1158

1159

1160

1161

1162

1163

1164

1165

1166

1167

1168

1169

1170

1171

1172

1173

1174

1175

1176 
1177 Figure 2

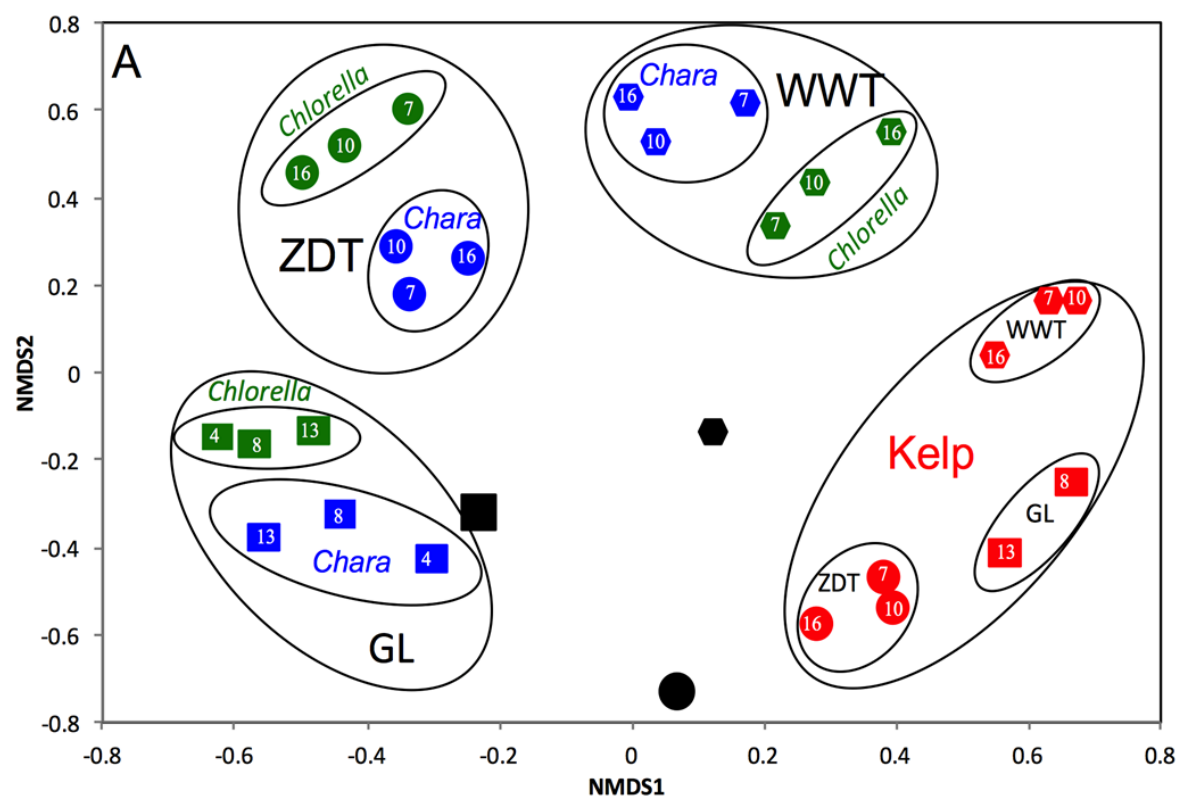

1178

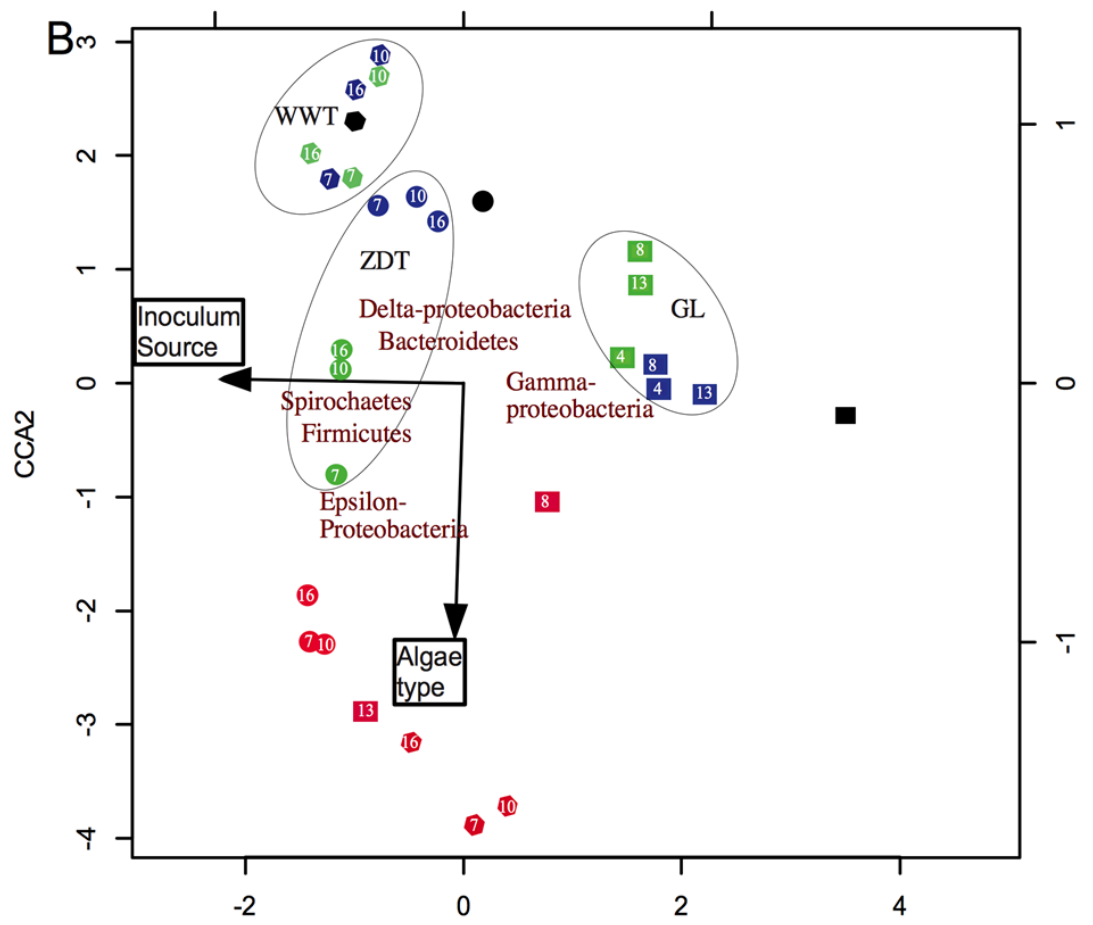

1179

1180

1181

1182

1183

1184

1185

1186

1187 
1188 Figure 3
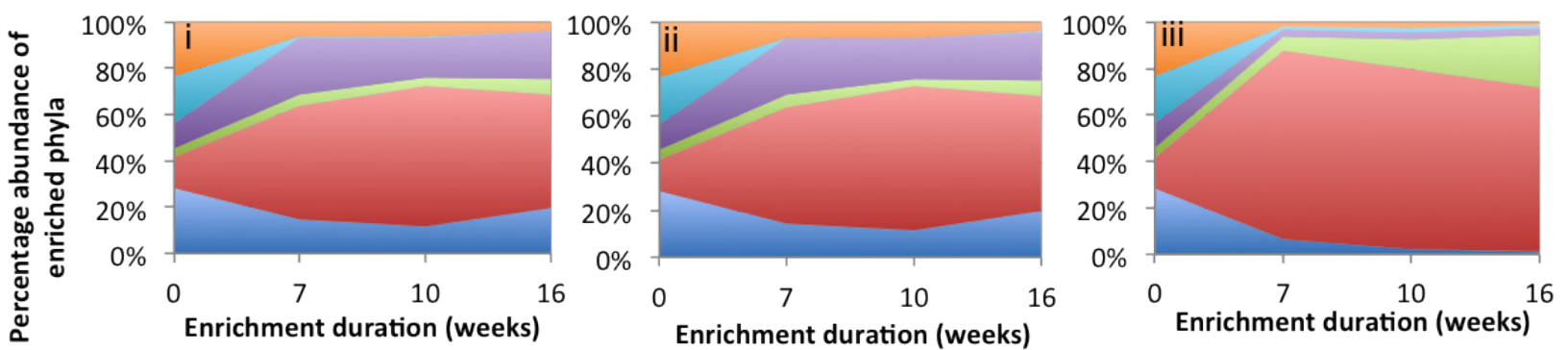

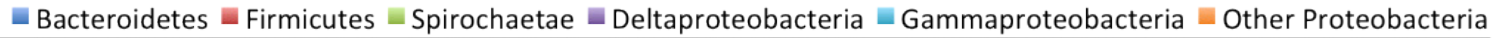

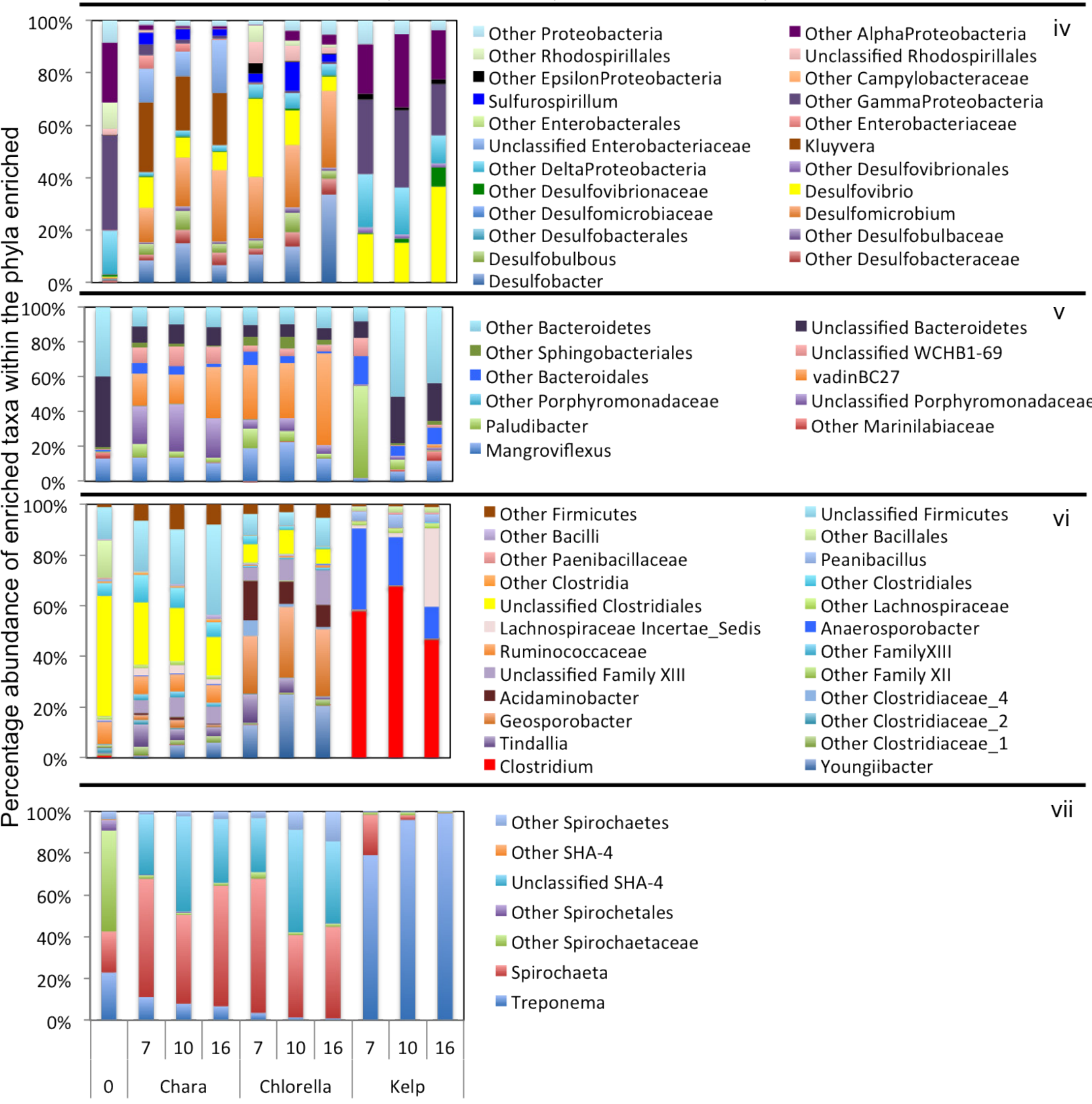


1190 Figure 4

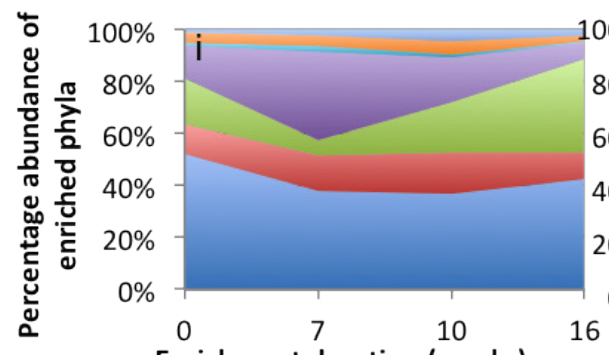

Enrichment duration (weeks)

abcteroidetes

- Gamma Proteobacteria

Eirmicutes

Epsilon Proteobacteria

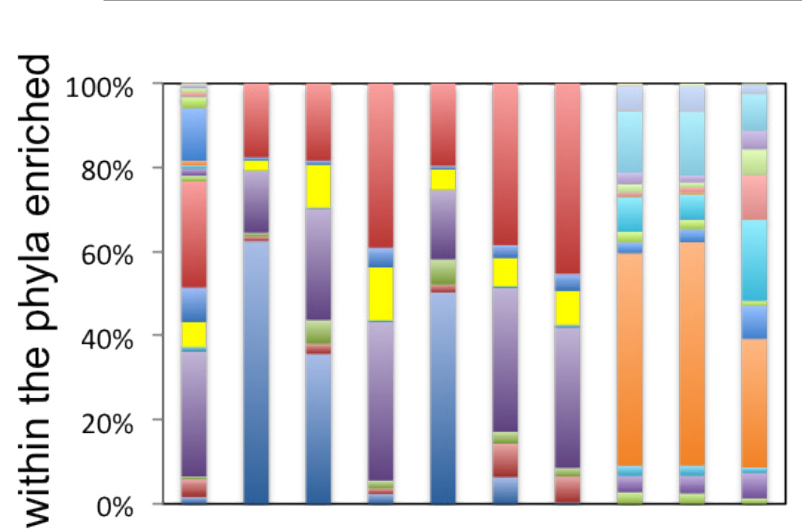

tே

त्ष

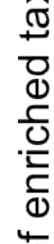



\section{(1)}

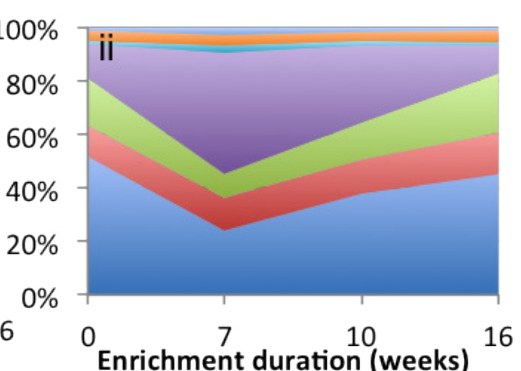

@ Spirochaetae

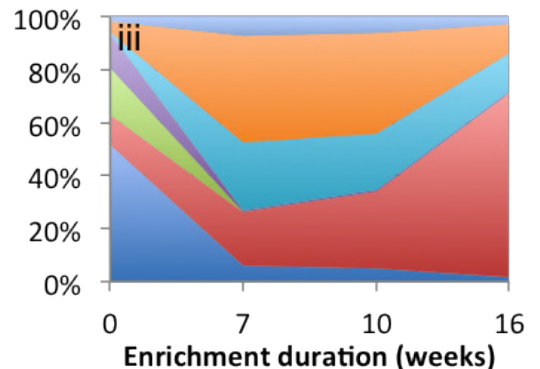

Enrichment duration (weeks)

Delta Proteobacteria

Other Proteobacteria

Other Gamma Proteobacteria

Other Pseudomonadales iv

Other Moraxellaceae

- Pseudomonadaceae

w other Enterobacteriaceae

unclassified Enterobacteriaceae Kluyvera

- Other Aeromondales

- Tolumonas

- other Campylobacterales

- Sulfurospirillum

- Other Aeromonadaceae

- other Epsilon Proteobacteria

- other Campylobacteraceae

Arcobacter

- Rhodocyclales

- Burkholderiales

Other Delta-Proteobacteria

vother Desulfovibrionaceae

- Other Proteobacteria

Other Desulfovibrionales

Desulfovibrio

- Other Desulfobacterales

- Other Desulfobacteraceae

Desulfobacter

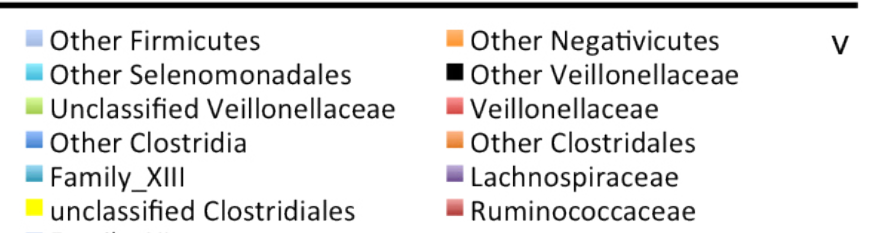

- Family_XI

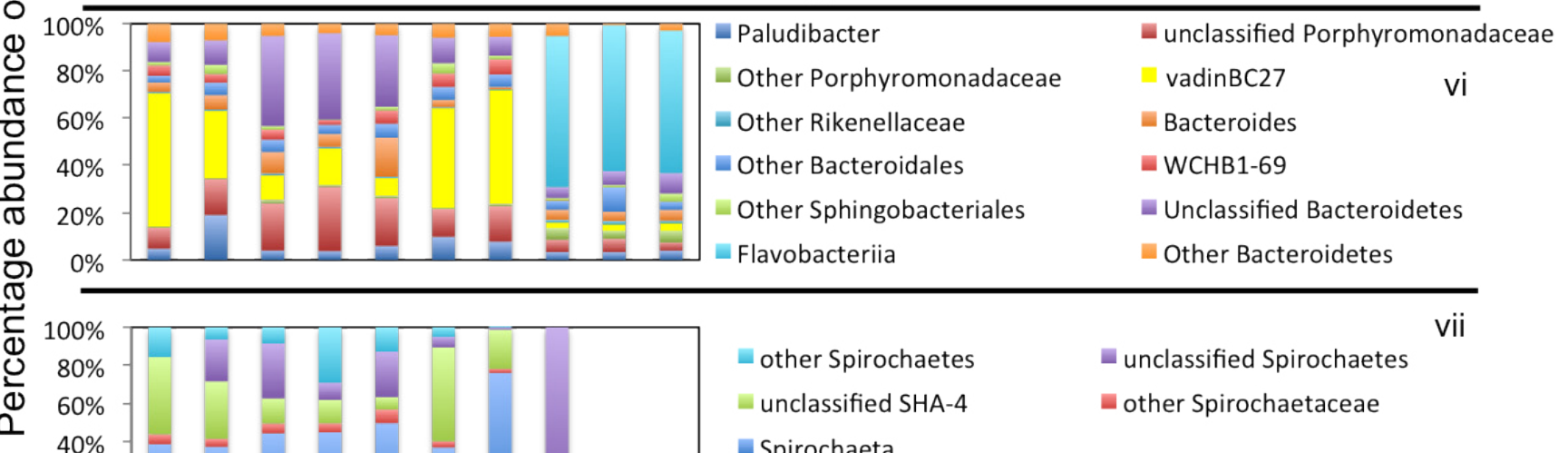




\section{Figure 5}
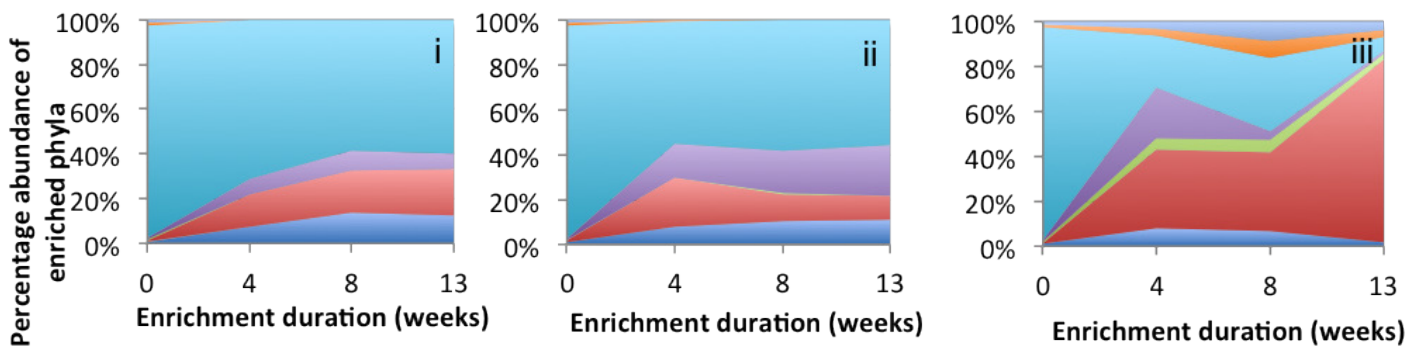

Bacteroidetes

Firmicutes

- Planctomycetes

Enrichment duration (weeks) - Gamma Proteobacteria $\quad$ Alpha Proteobacteria Beta Proteobacteria

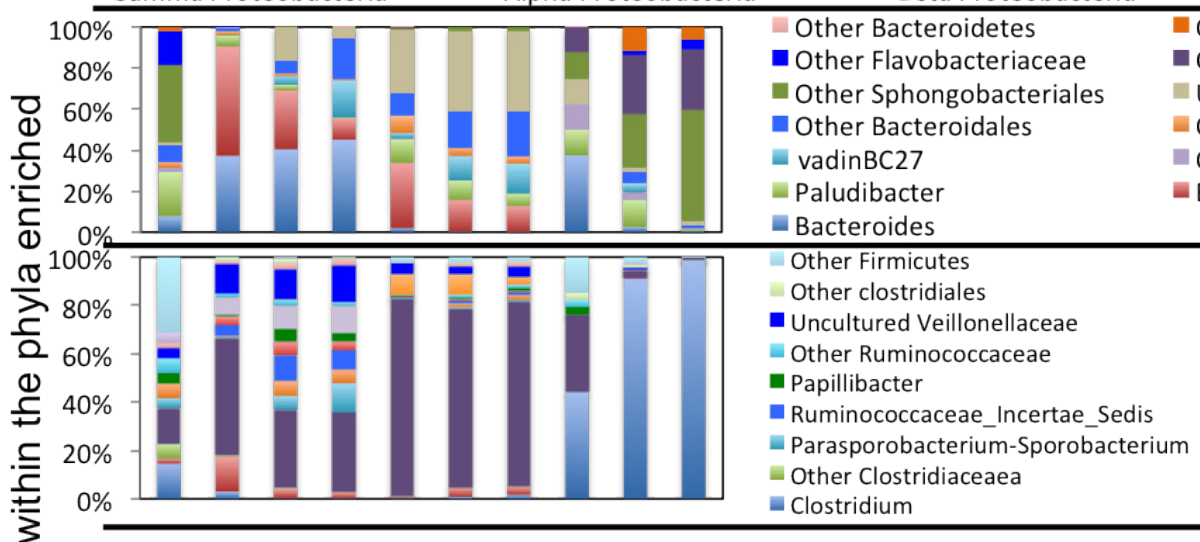

- Delta Proteobacteria

Other Flavobacteriales

- Chryseobacterium

- Unclassified WCHB1-69

- Other Rikenellaceae

Other Porphyromonadaceae

Barnesiella

Other Clostridia
Other Veillonellaceae V
Sporomusa
Ruminococcus
- Oscillibacter
- Other Lachnospiraceae
- Lachnospiraceae_Incertae_Sedis
= Oxobacter

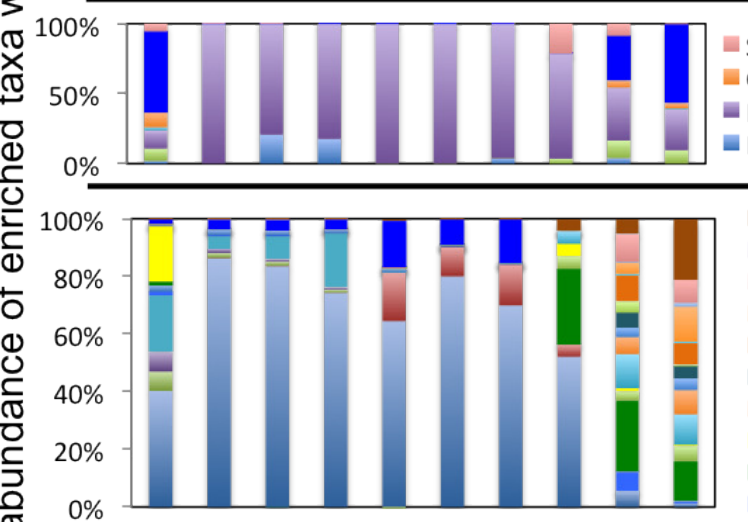

Sulfurospirillum

- Other Delta Proteobacteria

- Other Desulfovibrionales

- Other Desulfovibrionaceae

- Desulfovibrio

- Other Desulfobacterales

Desulfobulbus

- Other Gammaproteobacteria

- Other Aeromonadaceae

Other Aeromonadales

vii

Other Oceanospirillales

- Aeromonas

Marinomonas

- Other Oceanospirillaceae

- Cobetia

- Other Methylococcaceae

- Other Halomonadacea

- Other Methylococcales

Methylococcus

Methylomonas

- Methylocaldum

Other Pseudomonadales

Other Moraxellaceae

- Acinetobacter

Escherichia

- Other Enterobacteriaceae

Pantoea

Erwinia Citrobacter

ర)

Edwardsiella

- Buttiauxella

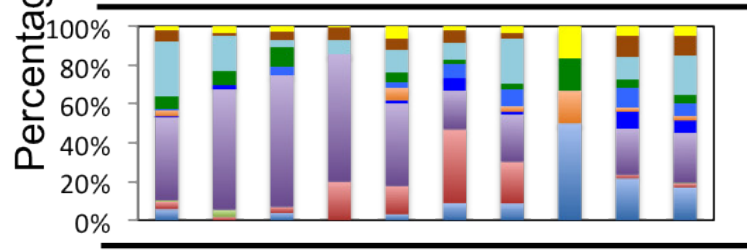

Other BetaProteobacteria

Nitrosomonadales

viii

Burkholderiales

Other Rhodocyclales

- Other Rhodocyclaceae

- Other Methylophilales

- Methylobacillus

- Uncultured Rhodocyclaceae

- Other Methylophilaceae

- Other Alpha Proteobacteria

- Other Sphingomonadales

= Other Sphingomonadaceae Sphingobium

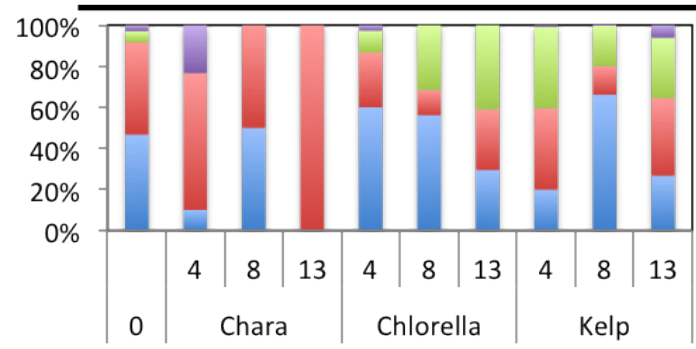

= other Planctomycetes

unclassified OM190

- Planctomycetaceae

= CL500-3 